\title{
The open-air site of Tolbor 16 (Northern Mongolia): preliminary results and perspectives
}

Nicolas Zwyns ${ }^{1,2^{*}}$, Sergei A. Gladyshev³, Biamba Gunchinsuren4, Tsedendorj Bolorbat ${ }^{4}$, Damien Flas ${ }^{5}$, Tamara Dogandžić2, Andrei V. Tabarev³, J. Christopher Gillam6, Arina M. Khatsenovich³, Shannon McPherron², Davakhuu Odsuren ${ }^{4}$, Cleantha H. Paine ${ }^{7}$, Khovor-Erdene Purevjal ${ }^{4}$, John R. Stewart ${ }^{8}$

*Corresponding author

Email: nzwyns@ucdavis.edu

\section{Introduction}

The mechanisms that lead to the appearance of the Upper Paleolithic are of major importance in order to evaluate models of emergence/dispersal of Anatomically Modern Humans (AMH) in Eurasia. Whether seen as a gradual phenomenon that takes place exclusively in Africa, or as a result of multiregional processes, it is clear that in certain regions the fixation of modern human anatomy might predate the recognition of a fully developed Upper Paleolithic package (e.g. Hublin, 2012). It is, therefore, crucial to clarify the nature of assemblages previously described as transitional or Initial Upper Paleolithic (IUP) (see Kuhn \& Zwyns, in this volume).

In the Altai, IUP has been recognized at Kara-Bom among other sites (e.g. Kara-Tenesh, Ust-Karakol 1 sector 1) and dated between 45 and 40 ka ${ }^{14} \mathrm{C}$ BP (Derevianko et al., 1993; Goebel et al., 1993). IUP retains Levallois-like typological features combined with innovative volumetric and subvolumetric blade core reduction (Derevianko \& Rybin, 2003). In North Asia, IUP most often includes a small blade component produced from a specific reduction method defined as the burin-core technology (Zwyns et al., 2012). The blade reduction pattern is mainly bidirectional and the flaking techniques are likely direct percussion with hard and soft hammerstone.

According to most authors, the Kara-Bom tradition is technologically, typologically, and chronologically distinct from the Ust-Karakol variant that first occurred following the Heinrich 4 event, circa 34 ka ${ }^{14} \mathrm{C}$ BP (Derevianko and Volkov, 2004; Derevianko, 2011; Goebel, 2004; Otte and

\footnotetext{
1. University of California, Davis, USA - 2 - Department of Human Evolution, Max Planck Institute for Evolutionary Anthropology, Germany $\cdot 3$ - Institute of Archeology and Ethnography, SBRAS, Novosibirsk, Russia - 4 - Institute of Archeology, MAS, Ulaanbaatar, Mongolia $\cdot 5$ - FRS-FNRS, University of Liege, Belgium $\cdot 6$ - University of South Carolina, USA $\cdot 7$ - University of Cambridge, UK $\cdot 8$ Bournemouth University, UK
} 
Derevianko, 2001; Otte and Kozlowski, 2003; Zwyns, 2012). The latter is mostly characterized by the presence of small laminar blanks (Kuzmin, 2004, 2007) obtained by direct percussion from small prismatic, carinated or flat-faced cores (Zwyns, 2012). Blade production shows various technological patterns including unidirectional semi-circular reduction with the introduction of organic hammer. With respect to these differences, the latter tradition can be referred to as Early Upper Paleolithic.

Based on the lithic assemblages and available chronological data, IUP can be recognized in the CisBaikal, in sites such as Makarovo-4 (Goebel and Aksenov, 1995) and in the Transbaikal, at Khotyk, Kamenka A-C (Lbova, 2008, Orlova et al., 2005) and in Podzvonkaya (Tashak, 2002). The similarities observed between the Altai IUP and assemblages from Cis- and Transbaikal (Rybin, 2000) and Northern and Central Mongolia suggest contact/movement of populations over long distances during the first half of MIS3 (Zwyns, 2012, Rybin, this volume) (Fig.1). Another interpretation proposed by scholars pleads for scenarios of multiple transitions from local Middle Paleolithic backgrounds (Derevianko and Shunkov, 2004; Derevianko, 2011). How to interpret the analogies and the variability of the lithic productions is still unclear and the mechanism leading to the emergence of IUP in these regions are still poorly understood.

Three main questions are highlighted. First, do the Altai and Northern Mongolia IUP reflect examples of a united techno-complex? Second, does the Selenga River Valley represent a corridor that would favor population movements? And third, what is the meaning of the change from IUP to EUP? With respect to the vast territories considered, the limited amount of high-resolution data available often stands as a significant obstacle to resolve these issues. In Mongolia, stratified site assemblages recognized as IUP are few. Located in the Central and Northern part of the country, most of these sites have been documented between 2000 and 2007 during the Joint MongolianRussian-American Expedition (JMRAE) (directed by D. Tseveendorj, A.P. Derevianko, J. Olsen) (for more details see also Gladyshev et al., 2012). One of the clearest reported sites is Tolbor 4 in the Ikh-Tulberiin-Gol (Tolbor) River Valley. Lithic assemblages from layers 5 and 6 show intriguing similarities with the Kara-Bom OH5-OH6 (Derevianko et al., 2007; Zwyns, 2012) and differ from the local EUP from the overlying layer 4 (Rybin et al., 2007) and from layers 6 and 7 at Tolbor 15 (Gladyshev et al., 2010b; 2012). By the presence of both UP variants and by its strategic geographical location, the Tolbor Valley is an appropriate area to address the above-mentioned research questions. 
In 2011, collaboration started between the Mongolian Institute of Archeology (Ulaanbaatar, Mongolia), the Max Planck Institute-EVA (Leipzig, Germany), and members of the JMRAE to excavate the newly discovered site of T16.

Fig. 1 Here (Full page)

\section{Geographical setting}

The Tolbor 16 (N49 13.619 E102 55.383) site is located in the Northern Hangai, along the western flank of the Tolbor valley (1169 m asl), some $13 \mathrm{~km}$ south of the confluence with the Selenga River (Fig.2). Cutting through the Western Sayan and the Yablonovy Ranges, the Selenga is one of the few low altitude passes that connects Siberia with the Northern part of Mongolia. With proximity to the Baikal rift, tectonic forces have significantly shaped the landscape. Active volcanism is well documented in Central and Northern Mongolia with basaltic vents and flows occurring between 30 million to circa 8,000 years ago (Barry et al. 2003; Chuvashova et al. 2007; Harris et al., 2010). Volcanic activity is particularly clear at the southern edge of the Tolbor valley with the Uran Togo volcanoes. Based on their morphology and based on comparisons with other Hangai formations, it is suggested that these volcanoes have been active until the Pleistocene (Harris et al., 2010; Hunt et al. 2012). Although volcanic formations represent the main geological substrate in the region (Badarch et al., 2002), judging by the amount of uplift and folding observed underlying sedimentary rocks are likely to be exposed in the Selenga basin. The upper parts of the hills are eroded with uncovered weathered volcanic rocks and siltstone outcrops. Around $85 \%$ of the annual precipitation (250-300 mm) falls in the valley between June and September. Currently, the average temperature is between $-0.9^{\circ} \mathrm{C}$ and $-1.6^{\circ} \mathrm{C}$ (and minima of $-46.2^{\circ} \mathrm{C}$ ) and the landscape is characterized by the Selenge-Orkhon forest-steppe. In the direct vicinity of the sites, the western slopes are covered by steppe grassland with a presence of boreal trees in the narrow canyons adjacent to the valley. Larch (Larix sibirica), Siberian and Scots pine (Pinus sibirica, Pinus silvestris), and White Birch (Betula platyphylla) occur on north facing slopes where the soils retain enough moisture to support them (Gillam et al., 2012).

Fig. 2 Here 
Like most of the numerous Paleolithic locations identified in the Tolbor Valley, T16 is located on the western bank of the river. It lies at the edge of one of the numerous seasonal streambeds of the Tolbor drainage system (Fig.3). The stream flows down from a mountain massif (1800 m asl), runs eastward across open grasslands and joins the Tolbor alluvial plain. Its clear-cut, undulating trajectory is drawn by a succession of semi-circular meanders that cut through Pleistocene deposits. The latest phase of erosion affects the uppermost soil formation and indicates that the extant morphology of the stream banks post-dates the end of the Pleistocene.

Fig. 3 Here

\section{Excavation methods}

The Tolbor 16 site was discovered in 2010 by S. A. Gladyshev and A. V. Tabarev (Gladyshev et al., 2010). Paleolithic artifacts were collected along the slopes of eroded meanders, where the canyon joins the open grassland. Two test pits along the edge of the semi-circular surface revealed the presence of preserved Paleolithic layers (Tabarev et al., 2012). The 2x1m test pits were oriented along the slope and were separated by a distance of $35 \mathrm{~m}$. Pit 1 is located between the stream and one of the numerous stone mounds that covers the western hillsides of the valley (Fig. 4). The fenced perimeter organized around a central mound is a typical of the Khirigsuurs, a variant of the 'Kurgan' in Mongolia (Fitzhugh, 2009). The test excavation was approximately 4m deep. The main artifact concentration was found approximately between $1.70 \mathrm{~m}$ and $2.00 \mathrm{~m}$ from the ground surface and no more artifacts were found below this. According to Gladyshev and colleagues, Pit 1 provided the best evidences for Paleolithic occupation whereas Pit 2, located at the top of the slope, yielded just a few artifacts. In the initial test pits artifact provenience was not systematically recorded and sediments were not screened.

Fig. 4 about here.

Following these preliminary tests, programmed excavations were carried out in 2011 and 2012, under the field direction of N. Zwyns. The methodology was adjusted in order to increase the resolution of data recording and to document site formation and anthropogenic processes (e.g. McPherron \& Dibble, 2002, Nigst et al. 2008). A total station was used for mapping the general topography of the site and anthropogenic features and recording artifacts larger than $2 \mathrm{~cm}$ in length. When possible, orientation and inclination of the long axis of artifacts was measured. The 
collected sediments were dry-sieved using a 2 and $4 \mathrm{~mm}$ mesh. Sample locations were recorded with the total station. All data were saved using a PocketPC (EDM Mobile software) and then transferred to MSAccess before being processed in GIS software (McPherron \& Dibble, 2002). Graphic documentation consists of geo-located digital pictures, hand-made and digital mapping, and situational sketches. The use of this standardized methodology allows for comparison between the Tolbor results and sites following the same protocols.

In 2011, after localization and mapping of Pit 1 and Pit 2, Pit 1 was re-opened and enlarged by $2 \mathrm{~m}^{2}$ northward and $1 \mathrm{~m}^{2}$ southward. A safety step was opened down slope within the uppermost soil formations. In 2012, $4 \mathrm{~m}^{2}$ were excavated, opening a total surface of $9 \mathrm{~m}^{2}$ with $3 \mathrm{~m}$ of cross-sections along each side. An additional one-half $\mathrm{m}^{2}$ was excavated down slope for stratigraphic purposes. In 2013, additional $5 \mathrm{~m}^{2}$ were excavated bringing the total surface to $14 \mathrm{~m}^{2}$. The excavated area was brought down until signs of human occupation could no longer be detected (max $2.40 \mathrm{~m}$ ). In 2012 and 2013, two additional pits, respectively Pit 3 and Pit 4 were opened in the meander of the nearby stream. Pit 3 is a $2 \mathrm{~m}^{2}$ test pit and Pit 4 is a $4 \times 1 \mathrm{~m}$ trench oriented according to the recognition of artifact-bearing unit 4 in the eroded section.

\section{Stratigraphy}

Fig.5 about here

The exposed stratigraphy has been divided into 7 units (Fig.5 above). The top of the sequence (units 1,2, and 3) contains two soils: a recent light-brown kastanozem-type soil (unit 1)(Fig. 5.A) and a darker brown chernozem-type soil (unit 2) (Fig. 5.B) with a weak $B_{k}$ horizon(unit 3) (Fig. 5.C); large root marks extend from unit 2 into unit 4, and fine roots mark the boundary of units 3 and 4. The soils are formed on loess parent materials, but they record at least one debris flow episode, indicating the intermittent continuation of the fan-type sedimentation observed deeper in the section. The middle portion of the sequence comprises typical pale yellow loess (unit 4) (Fig. 5.D) with sandy lenses. Loess-like sediments affected by cryoturbation/solifluction (unit 5/6) (Fig. 5.E) include lenses of a possible weak humic horizon, slightly darker in color. The lower portion of the section (unit 7) (Fig. 5.F) is a succession of finely laminated poorly sorted whitish to lightbrown sediments; very fine silt and sand predominate, but the laminar sediments include gravel, pebbles, and cobbles, and display some size sorting between laminates. It is unclear at present 
whether color variation here results from substantial compositional differences. Some laminates display distinctive undulating structures, which hints at the unit's mode of deposition. Unit 7 sits at the top of what is likely to be a very deep sequence of alluvial fan sediments, and probably result from a combination of low-energy fan and slope sediment transport processes (colluviation, sheet erosion or gelifluction). The remarkably angular cobble-sized inclusions in these sediments may have rolled downhill from a nearby bedrock outcrop. Gravitational input could partly explain the lack of size-sorting observed within the laminates.

Except for a few lithic artifacts and a single potsherd, units 1, 2 and 3 are archeologically sterile. Clear signs of human occupation occur starting from unit 4. Artifacts are scattered throughout the whole sedimentary unit with a relatively low density. Unit 5/6 is richer in archeological material, however, the distribution of the finds combined with the shape of the sedimentary unit clearly indicate post-depositional movements. Unit 7 has yielded the richest archeological assemblage. It consists of a $30-40 \mathrm{~cm}$ thick accumulation of lithic and bone remains that follow a slope comparable to the present day surface. Possible evidence for the use of fire affected by low energy postdepositional processes has been discovered (see below).

\section{Taphonomy and artifact orientation}

According to Bertran and colleagues (1997), fabric analyses help to discriminate collective particle movements (e.g. solifluction, debris flow and mudslide) with artifact orientation following the slope from single-particle movement (e.g. run-off, rock fall) with planar or isotropic artifact orientation. At Tolbor 16, artifact orientations were recorded for elongated artifacts and bones. Horizontal (bearing) and vertical (plunge) orientations were calculated based on coordinates of their endpoints (McPherron, 2005). The bearing can reveal potential effects of stream flow when it shows significant alignment. In undisturbed deposits, artifact plunges usually follow slopes of the surface where they are deposited. The sample size required to perform statistical analysis is obtained when unit 7 is considered as a whole ( $N=121)$ (Fig.5-2). Results show that the mean bearing angle for this layer is 175.67 ( $S D=102.4)$ and the mean plunge value of $11.03(\mathrm{SD}=14.18)$. Rayleigh test of uniformity does not show any preferred artifact bearings $(p=.25)$ but shows significant preferred artifact plunge $(p=<.01)$ with an average dip of $11^{\circ}$. The latter is similar to the average current hill slope of $9.5^{\circ}$ (Fig.6-A). 
Fig. 6 around here

Table 1 here

On the Benn diagram (Fig.6-B, Table 1), the fabric of lithic artifacts and bones fall into the range of individual particle movements, such as a run-off (e.g. Lenoble \& Bertran, 2004). This observation is consistent with the sedimentary context of a laminated, poorly sorted, sandy-silt deposit. Fabric, however, are only indicative of the last deposition episode. The site of T16 is located along a $10^{\circ}$ slope with low vegetation cover. Currently, the climate is highly contrasted temperatures and hygrometry. Sub-zero temperatures prevail from September to May and are then followed by a rainy season. This suggests that even at relatively low elevation, freeze-thaw and periglacial processes similar to those observed in higher elevation (Bertran et al., 2010) may have played a role in the site formation.

The particle size distribution in a lithic concentration is also a sensitive marker to address taphonomic issues in an archeological context (Schick, 1986). Dramatic size sorting would indicate that artifacts have been re-deposited as opposed to a situation where small fraction matches the experimental referential. Bertran and colleagues (2012) suggest that other factors, such as the kind (and the stage) of reduction sequence, the size of the endproducts, the raw material, the preparation of platform (e.g. faceting), the skill of the knapper, and trampling may have an impact on the frequency of small lithic artifacts. At T16, the small fraction is partly preserved in unit 4, unit 5/6 and unit 7 (Fig A-below). Unit 7 stands out by containing more artifacts larger than $2 \mathrm{~cm}$. Mostly, they document a production of blade on site, from the massive blank to the exhausted core. Compared with an experimental blade production on flint (Bertran et al., 2012), a deficit of about $20-25 \%$ in the frequency of $<2 \mathrm{~cm}$ lithic is observed. Differences with published experiments may also reflect the lack of wet screening or for the difficulty to identify the small lithic fragments (as opposed to natural debris). To address this issue, a particle size analysis with a specific experimental protocol is in progress.

\section{Lithics}

Pit 1 has yielded 1974 piece-plotted artifacts $(>2 \mathrm{~cm}$ ). Newly excavated Pit 4 includes 380 pieceplotted artifacts over $4 \mathrm{~m}^{2}$. So far, 7094 lithics have been found in the dry-screening (>2mm) (Fig.5- 
3). The dominant raw materials in the collection are metamorphic sedimentary rocks (aleurolite/siltstone) and igneous rocks (basalt and rhyolite) with the occasional occurrence of chert, jaspoids or other highly silicified material in unit 4 and unit 5/6. The latter material is virtually absent in the unit 7 . Although quite variable in terms of grain size and patina, the most frequent raw material is light to dark grey medium grain siltstone/aleurolite. It occurs in bands sandwiched between two layers of basaltic rocks in a primary outcrop located $100 \mathrm{~m}$ away from the excavation area. Cryogenic cracks are frequent in extant available nodules but are also observed on the archeological sample. Another primary outcrop has been identified approximately $750 \mathrm{~m}$ upstream, in the high hills. Preliminary observations on the assemblage of unit 7 from Pit1 are presented below.

Table2 here

The following observations are made based on piece-plotted artifacts $(\mathrm{N}=1076)$. The analysis of the artifacts from the screen $(<2 \mathrm{~cm})$ is still in progress. Among the blanks, the frequency of blade and flake is roughly equal $\left(\chi^{2}(1, N=1076)=3.36, p=.07\right)$. The abundance of cores/core preforms indicates that knapping activities were taking place on site. Blade and flakes blanks are mostly noncortical (64\% of 574 blanks). This number might also reflect the difficulty to distinguish natural surfaces/primary cortex from the post-depositional slight patina. Among the laminar blanks, crested blade blanks (11\%) including initial, second and neocrests (Fig. 7;17) of various sizes indicate a relatively high intensity of the blade production. Beside the preforms, cores with unidirectional and bidirectional (opposed platforms) are equally represented $(\mathrm{N}=16)$. The presence of a few flake cores is noted $(\mathrm{N}=3)$ including two discoid examples. Both bidirectional $(30 \%)$ and unidirectional (36\%) dorsal patterns are observed in similar frequencies $\left(\chi^{2}(1, N=282)=2.32, p=\right.$ .12) with some classified as undetermined (23\%) when the raw material surface and/or carbonate concretions did not allow a clear technological reading. The blade platforms $(\mathrm{N}=102)$ are mostly plain (41\%), facetted (23\%) and dihedral flat (12\%). Evidence for specific preparations with marginal faceting/overhang removal $(12 \%)$ on plain or dihedral platform also occurs. The external platform edges are mostly abraded (47\%) sometimes intensively with occasional impacts suggesting that the edge has been hammered. The mean platform thickness $(5.1 \pm 3 \mathrm{~mm})$ can be characterized as thick according to Pelegrin's definition $(>4 \mathrm{~mm})$. The large standard deviation reflects a bimodal distribution of the platform thickness. In a mixture analysis model (Log likelihood -144.5, Akaike IC 297.4), the first mode represents $65 \%$ of the set with relatively thick 
platforms $(3.5 \pm 1.3 \mathrm{~mm})$. The second mode $(7.9 \pm 3.1 \mathrm{~mm})$ accounts for the remaining $35 \%$ of the blade production and has exceptionally thick platforms. A frequent inward percussion on a tough raw material could indicate the frequent use of stone hammers. When combined with the presence of overhang removal by strong abrasion or marginal flaking, it could also indicate the use of a soft hammerstone (Pelegrin \& Inizan, 2013). The identification of the flaking technique, however, requires a specific analysis that is beyond the scope of the present paper. Bladelet cores $(\mathrm{N}=5$,) (Fig. 7:8-10) have been uncovered at the top of unit 7 and at the interface between unit 4 (unit 5/6). Not surprisingly, bladelets are rarely piece-plotted and their frequency increases when blank and fragments from the screen material will be included ( $\mathrm{N}=>22$, in progress). The lower part of the lithic concentration lacks evidence for a systematic bladelet production. Two burin-cores have been found but judging by the size of the last negatives, they testify to the production of small blades rather than bladelets $(<12 \mathrm{~mm}$ width).

Fig.7 around here

The following observations are derived from the piece-plotted retouched flake and blade blanks. Retouched tools on blades significantly dominate $\left(\chi^{2}(1, N=547)=6.685, p=<.01\right)$. Among the main tool types are the retouched blades $(\mathrm{N}=76)$, notched blades $(\mathrm{N}=7)$ and blades with denticulations $(\mathrm{N}=7)$ or truncations $(\mathrm{N}=3)$. The presence of a single endscraper is noted. A mesial fragment with inverse retouch and a blank with alternate retouch represent the piece-plotted bladelet tools. Tools on flakes and fragments include retouched flakes $(\mathrm{N}=34)$, scrapers $(\mathrm{N}=8)$ with the notable presence of transverse specimen ( $\mathrm{N}=2)($ Fig.7; 5), notches $(\mathrm{N}=7)$, denticulates $(\mathrm{N}=4)$ and endscrapers $(\mathrm{N}=4)$ (including a transversal endscrapers and an endscraper on debordant flake). Notable is the presence of a perforator and of a Levallois flake.

\section{Ornaments}

In 2013, two complete beads were found in Pit 1 and Pit 4, respectively, from unit 7 and unit 4. They are circular in shape with a maximum diameter of 6.9-7.1 mm. Their thickness of $1.9 \mathrm{~mm}$ falls in the range of ostrich eggshells (OES). One of the beads (Fig. 8 above) has been found in Pit 4 in an area that shows evidence for sediment reworking (unit 4-5/6). It bears a regular perforation with an aperture of $3 \mathrm{~mm}$ in diameter. The second (Fig. 8 below) was found associated with the upper part of unit 7 in Pit 1 . The perforation has an aperture with a maximum diameter of $4.4 \mathrm{~mm}$. The 
circular bevel observed on both sides of the two beads suggests a bidirectional perforation technique.

Fig. 8. Around here

Published referential on South African material is used here as an example for comparison. The general shape of the beads retains angles that have been heavily smoothed, suggesting that the manufacture stages have been completed for the most part (stage 11 in Kendall and Conard 2005, VI-VII in Orton, 2008). Based on Kendall and Conard (2005) classification in two groups, the beads from T16 fall into the 'large' category (diameter of $>5 \mathrm{~mm}$, with a mean between of $6.68 \pm 0.99$ $\mathrm{mm}$ ); based on three categories used by Orton (2008), they also fit in the 'large' group (>6 mm). T16 beads have a maximum diameter that falls into the range of the OES beads from Early Later Stone Age at Border Cave (d'Errico et al., 2012). One of the T16 has perforation diameter that falls outside of the standard deviation of this referential. Based on the aperture/thickness ratio, Orton (2008) suggests that a large aperture corresponds to an extended wear and is a good indicator for duration of use. The correlation observed in his data set predicts that with a thickness of $1.9 \mathrm{~mm}$, the aperture would not be larger than $1.6 \mathrm{~mm}$. With a much larger aperture, the perforation of T16 beads in the T16 does not follow this prediction. Thus, it is unclear if it corresponds to a long duration of use or if the perforation was initially larger.

Two similar finds have been reported associated with the early stages of Upper Paleolithic at Dörölj-1 (Jaubert et al., 2004). The latter have highly comparable diameters of 6-7 mm. According to the description by Y. Taborin, one of the beads has regular outline but with a coarse aperture, the other has regular aperture but with a more regular outline. Based on the publication, the former has a perforation circa $2.5 \mathrm{~mm}$ whereas in the latter, the aperture exceeds $3 \mathrm{~mm}$ in diameter. A fragment reported from layer 5 at Tolbor 4 may represent a similar object (Derevianko et al., 2006). OES beads are the earliest evidence for symbolic behavior in Mongolia.

\section{Faunal remains}

So far, 49 piece-plotted bones and teeth and 213 screened bones have been uncovered. The general state of preservation of the bone material is challenging morphological identifications and some of the bones appear to be weathered and fragmentary. First observations indicate the occurrence of 
Equus sp. and a large bovid within unit 7 and tentatively identified Equus sp. in unit 6. Fragments of OES have been found in unit 4 and unit 7. These taxa are not unexpected for deposits of this age north of the Hangai (Simonet et al., 2012) up to the Baikal region (Germonpre \& Lbova, 1996 ; Khenzykhenova et al., 2011, Janz et al., 2009). They are generally associated with open habitat including grasslands.

\section{Combustion features}

During the 2011 excavations, two potential combustion features were recognized in Pit 1. Apart from a small fragment of burned bone, no charcoal remains were identified. The coloration of the burned sediment and the occurrence of ash would indicate localized combustion features associated with the archeological assemblage from unit 7. A few additional patches of burned sediments have been identified in the vicinity in 2012. These potential features are likely affected by post-depositional processes and pending the results from the soil micromorphology analyzes, their association with anthropogenic activities is suspected, but not confirmed.

\section{Chronology}

The Paleolithic record of the Tolbor Valley is remarkably rich, but so far, only a handful of radiocarbon dates have been obtained on bone and ostrich eggshells samples in two different labs. One of the challenges is to obtain comparable results for some of the key sites in the valley by using a standardized methodology. This will in turn increase the resolution of the regional sequence proposed by Gladyshev and colleagues (2010a) and more generally, the chronology of UP sites in Mongolia (Orlova et al., 2005).

In 2011, a first series of ${ }^{14} \mathrm{C}$-AMS dates has been obtained from the Tolbor 16 and Tolbor 15 sites (Table 3). In addition, two ${ }^{14} \mathrm{C}$-AMS dates were obtained on bone samples from the newly discovered Tolbor 21 site (Tabarev et al., 2012, Gladyshev et al., 2013). Samples were selected for dating when showing a satisfying amount of collagen yield ( $>1 \%$ ) (Ambrose, 1990,Weber et al., 2005 ; Hublin et al., 2012) and C:N between 2.9 and 3.5 (Klinken, 1999). The samples were pretreated at MPI-EVA Leipzig using the method described in Talamo and Richards (2011). Approximately $500 \mathrm{mg}$ of samples were first cleaned and then demineralized in $0.5 \mathrm{M} \mathrm{HCl}$ at room 
temperature until no $\mathrm{CO}_{2}$ effervescence could be observed. $0.1 \mathrm{M} \mathrm{NaOH}$ were then added for 30 minutes to remove humics. The $\mathrm{NaOH}$ step was followed by further rinsing with $0.5 \mathrm{M} \mathrm{HCl}$ for 15 minutes. The sample was then gelatinized, following Longin (1971), in a pH3 solution at $75^{\circ} \mathrm{C}$ for 20h. The resulting gelatin was first filtered in an Eeze-Filter ${ }^{\mathrm{TM}}$ (Elkay Laboratory Products (UK) Ltd.) to remove small $(<8 \mu \mathrm{m})$ particles and then through a $30 \mathrm{kDa}$ ultrafilter (Sartorius "Vivaspin 15”) (Brown, et al., 1988). Prior to use the filter was cleaned to remove carbon containing humectants (Brock, et al., 2007). The sample was then lyophilized for 48 hours. The selected samples were dated by AMS at the Klaus-Tschira-Labor für Physikalische Altersbestimmung (CurtEngelhorn-Zentrums für Archäometrie), Mannheim, Germany (Kromer et al., 2013).

Table 3 here

At T16, the single date (AA-93134) obtained prior the programed excavation provided an infinite age for unit 7, but the exact position of the bone sample was not recorded. In the current project, the first date obtained for the upper part of unit 7 indicates an age of $33,320 \pm 180{ }^{14} \mathrm{C}$ BP $(37,698 \pm$ 641 calBP). A single result is insufficient to provide an accurate chronological attribution for unit 7 as it may represent a minimum age for the underlying occupation. Interestingly, this result falls in the lower range of the new dates obtained for the layer 7 at T15 (between 37.5 and 40.5 ka 68\% range calBP).

\section{Discussion}

In order to answer the main research questions addressed in this project, the integrity the earliest human occupation at T16 must be properly assessed. So far, it has been identified in the horizontal bedded/cross-bedded sedimentary complex. In this unit, artifact orientation is consistent with a relatively low-energy sedimentation. The high frequency of concretion/crust on the lithic artifacts and the localized undulated bedding observed in the exposed sections could indicate damp/run off episodes taking part in the formation of the layer. The geographical setting of the site suggests that a combination of freeze/thaw cycles and slope processes have to be considered. The first observations on artifact orientation can only be fully understood when placed in the context of the site formation processes (analysis in progress). Further analyzes (sedimentology and soil micromorphology) to reconstruct the post-depositional history of the T16 unit 7 assemblages are in progress. 
Comparison with other archeological assemblages will help to discuss the place of T16 earliest occupation in the regional context. The main technological features in unit 7 are linked with the blade technology. Blade blanks occur in high frequency and their dorsal patterning indicate bidirectional reduction. Alternate short series of blanks are detached from cores with two opposed platforms and the crest is used for the management of convexities. Along with the occurrence of asymmetrical flat-faced cores, typical burin-cores and facetted debordant platforms on blanks, these features indicate affinities with the T4 assemblage of OH5 and OH6. They are generally consistent with the typical set of IUP features as defined at Kara-Bom in the Altai (Zwyns, 2012). Numerous retouched blades, a good representation of notches and denticulates, the coexistence of scrapers and endscrapers and the lack of simple types of burins are typological elements that reinforce this comparison. In this context, the discovery of a mesio-proximal fragment of convergent Levallois-like blade with inverse proximal thinning (Fig.7:4) is meaningful. This retouch comes close to a typological marker of Siberian Altai IUP (Rybin, in this volume), although the latter are usually made on blades with parallel edges.

Bladelet blanks are common in IUP contexts, but the occurrence of prismatic and carinated bladelet cores is, however, unusual. These cores are located at the top of unit 7 and in unit 5/6, whereas bladelets/fragments identified so far $(\mathrm{N}=29)$ occur down to the first half of unit 7 . For the most part, cores are located in reworked stratigraphic context. In the other sites of the Tolbor valley, genuine production of small laminar elements obtained by direct percussion is more commonly attributed to the EUP. At T4 (OH4), bladelet cores are associated with a flake-based EUP assemblage (Rybin et al. 2007). At T15 sites (OH5, OH6), this technology occurs alongside with a high frequency of blades detached from single platform cores (Gladyshev et al., 2012). Meanwhile, bladelet technology is described at Dörölj-1 (Jaubert et al., 2004) and is common in other assemblages from Siberia (e.g. Ust-Karakol 1, Anuy 3). Another point of comparison between Dörölj-1 and T16 are OES beads. At Dörölj-1 they are found in a layer dated between 33.8 and 37.6 ka cal BP. At T16, this technology would be between 37-38 ka calBP based on the single radiocarbon date available for the upper part of unit 7. Given the chronological ubiquity of this type of ornament in Mongolia, Northern China (e.g. Janz et al., 2009) and in Africa, it is still unclear whether the presence of these beads reflects cultural affinities or convergences. Larger sample size, more detailed analysis and additional chronological data are needed to address these issues. 
The chronological overlap with Dörölj-1 EUP is minimal. The earliest date obtained for this site (and the best match with T16) is derived from an OES bulk sample (Jaubert et al., 2004) whereas the date from T16 was produced on a bone sample. In the frame of the present project, three new dates were obtained on bone samples from the EUP assemblage of layers 6-7 (see also Gladyshev et al, 2013). The results on bones are consistently older and overlap with those on OES only at $2 \sigma$. Why the OES samples yielded significantly younger results is still unclear and comparisons between dates from OES and bone samples are problematic. Based on the new dates on bone samples, the EUP first occurs at T15 soon after the Heinrich 4 event, between 40.5 and 37.5 cal BP. With both dates produced on bone samples, pre-treated and dated in the same lab, the comparison with T16 unit 7 might be more meaningful.

In sum, the T16 has yielded an archeological sequence with a succession of at least two, if not three upper Paleolithic complexes. Unit 7 in Pit 1 has yielded a blade assemblage with general typotechnological features consistent with the IUP techno-complex. This technology marks a rupture with the pre-MIS3 flake-based assemblages (e.g. Tsagaan-Agui, Orkhon-1 and Orkhon-7) (Derevianko et al., 2004 ; Derevianko et al., 2010). The bladelet cores and a radiocarbon date circa 37-38 ka cal BP suggest a possible subsequent presence of EUP in the upper part of unit 7. An alternative explanation would be that T16 captures diachronic changes within the IUP technocomplex. The next step of the project is to address these questions in light of site formation processes. More generally, a dating program with unified protocols would help for the comparisons between the different sites of the region. Although the results presented here are preliminary, they underline the relevance of T16 site to investigate the beginnings of Upper Paleolithic in Northeast Asia.

\section{Acknowledgements}

We are grateful to the Leakey Foundation, the Max Planck Society and the Russian Fund for Science and Humanities for their financial and logistical support. Finnancial support was also brought by the Russian Foundation for Basic Research, Grant \# 12-06000037a and \# 14-06-00163a. We would like to thanks Sahra Talamo and Michael Richards for their participation. Our gratitude goes to all the people who took part in the excavation and to the Governor of the Bulgan Aimag for supporting this research. We would like to thanks Gao Xing and Robin Dennell for inviting us to contribute to the present volume and we thanks the anonymous reviewers for their help in improving this paper. 
Last but not least, we are grateful to the organizers and participants of the Shuiddongou Conference and to the authority of Ningxia for their hospitality.

\section{Figure captions}

Fig. 1: Map with the location of the main stratified sites yielding early blade assemblages in the region. 1. Kara-Bom, 2., Makarovo-4, 3. Khotyk, 4. Kamenka A-C, 5. Podzvonkaya, 6. Dörölj-1, 7. Tolbor sites (T4, T15, T16, T21), 8. Orkhon sites (Orkhon-1, Orkhon-7), 9. Tsatsyn Ereg-2, 10. Tsagaan-Agui, 11. Chikhen-2, 12. Shuiddongou-1 and -2. Adapted from Geoatlas.com.

Fig. 2: Map showing the location of the main stratified sites in the Tolbor Valley (courtesy of J.C. Gillam)

Fig. 3: Western Flank of the Tolbor Valley with the location of T16 site (photo courtesy of N. Zwyns)

Fig. 4: 1.Topographic map of the excavation area. 2. Longitudinal section of the hill slope. 3. Crosssection of the stream next to the site.

Fig. 5: Above: stratigraphic schema from the Northern wall, in pit 1. Legend: A. Organic deposit. B. Loess-like sediment. C. Loess with sandy lenses. D. Darker sandy-loess. E. Laminates. Combustion features are project from less than $1 \mathrm{~m}^{2}$. Dates are projected from $1 \mathrm{~m}^{2}$ and $3 \mathrm{~m}^{2}$. Below: frequency of artifacts by size for unit $4(\mathrm{~N}=2694)$, unit 5/6 (N=2373) and unit $7(\mathrm{~N}=4382)$.

Fig. 6: Artifact orientation. A. Schmidt diagram equal area and artifact average plunge. B. Benndiagram.

Fig. 7: Example of lithics from Unit 5/6 and Unit 7. 1 (drawings by Dogandžić \& Zwyns). Blade with proximal retouch. 2-3, Small laminar blanks, 4. Blanks with inverse proximal retouch, 5. Transversal convex scraper. 6, Flake with orthogonal dorsal pattern, 7. Blade core, 8-10. Bladelet cores. 11-13, Blades with platform bludgering and trimming. 14-16, 19-20. Blade with bidirectional dorsal pattern. 17., Neo-crested blade, 18. Large cortical blade.

Fig. 8: Ostrich egg shell beads. Above: Pit 4, unit 4-5/6. Below: Pit 1, unit 7. 
Table 1: Artifact orientation. Eigenvalue (E), Isotropic index (IS), Elongation Index (EL)

Table 2: Lithic sample from Unit 7

Table 3: Summary for the radiocarbon dates available for the Tolbor Valley Upper Paleolithic. Shaded rows indicate results obtained through MPI-Leipzig/ Klaus-Tschira-Labor für Physikalische Altersbestimmung (for more details concerning the dates obtained by other labs see also Gladyshev et al., 2010 ; 2013). Dates are calibrated using Online CalPal vers. 1.5 (2007).

\section{References:}

Ambrose, S.H., 1990. Preparation and characterization of bone and tooth collagen for isotopic analysis. Journal of Archaeological Science 17 (4), 431-451.

Badarch, G., Cunningham, W.D., Windley, B.F., 2002. A new terrane subdivision for Mongolia: implications for the Phanerozoic crustal growth of Central Asia. Journal of Asian Earth Sciences 1, 87-110.

Barry, T.L., Saunders, A.D., Kempton, P.D., Windley, B.F., Pringle, M.S., Dorjnamjaa, D., Saandar, S., 2003. Petrogenesis of Cenozoic basalts from Mongolia: evidence for the role of asthenospheric versus metasomatized lithospheric mantle sources. Journal of Petrology, 1157-1182.

Bertran, P., Hetu, B., Texier, J.-P., Van Steijn, H., 1997. Fabric characteristics of slope deposits. Sedimentology 44, 1-16.

Bertran, P., Klaric, L., Lenoble, A., Masson, B., Vallin, L., 2010. The impact of periglacial processes on Palaeolithic sites: The case of sorted patterned grounds. Quaternary International 214, 17-29.

Bertran, P., Lenoble, A., Todisco, D., Desrosiers, P.M., Sorrensen, M., 2012. Particle size distribution of lithic assemblages and taphonomy of Palaeolithic sites. Journal of Archaeological Science 39, 3148-3166. 
Brantingham, P.J., Krivoshapkin, A.I., Jinzeng, L., Tserendagva, Y., 2001. The Initial Upper Paleolithic in Northeast Asia. Current Anthropology 42, 735-746.

Brock, F., Ramsey, C.B., Higham, T., 2007. Quality assurance of ultrafiltered bone dating. Radiocarbon 49, 187-192.

Brown, T.A., Nelson, D.E., Vogel, J.S., Southon, J.R., 1988. Improved collagen extraction by modified Longin method. Radiocarbon 30, 171-177.

Chuvashova, I.S., Rasskazov, S.V., Yasnygina, T.A., Saranina, E.V., Fefelov, N.N., 2007. Holocene volcanism in Central Mongolia and Northeast China: Asynchronous decompressional and fluid melting of the mantle. Journal of Volcanology and Seismology 6, 372-396.

d’Errico, F., Backwell, L., Villa, P., Deganog, I., Lucejkog, J.J., Bamford, M.K., Higham, T.F.G., Colombinig, M.P., Beaumont, P.B., 2012. Early evidence of San material culture represented by organic artifacts from Border Cave, South Africa. Proceedings of the National Academy of Sciences of the United States of America 109, 13214-13219.

Derevianko, A. P., 2011. The Upper Paleolithic in Africa and Eurasia and the Origin of Anatomically Modern Humans. Institute of Archeology and Ethnography SB RAS, Novosibirsk.

Derevianko, A.P., Brantingham, P.J., Olsen J.W., Tseveendorj, D., 2004. Initial Upper Paleolithic blade industries from the north-central Gobi Desert, Mongolia. In: Brantingham, P.J., Kuhn, S.L., Kerry, K.W. (Eds.), The Early Upper Paleolithic beyond Western Europe. University of California Press, Berkely, pp. 207-222.

Derevianko, A.P., Kandyba, A.V., Petrin, V.T., 2010. Paleolit Orkhona (The Paleolithic of Orkhon). Institute of Archeology and Ethnography SB RAS, Novosibirsk.

Derevianko, A.P., Nikolayev, S.V., Petrin, V.T., 1993. The dating of the Paleolithic Kara-Bom site with physical methods (C14 and EPR). Altaica 3, 2-8. 
Derevianko, A.P., Rybin E.P., 2003. Drevneyshee proyavlenie simvolicheskoy deyatel'nosti paleoliticheskogo cheloveka na Gornom Altae (The earliest evidences of simbolic activity of paleolithic man in the Altai Mountains). Archaeology, Ethnology and Anthropology of Eurasia, 15, 27-50.

Derevianko, A.P., Volkov, P.V., 2004. Evolution of lithic reduction technology in the course of the Middle to Upper Paleolithic transition in the Altai Mountains. Archeology, Ethnology and Anthropology of Eurasia 2, 21-35.

Derevianko, A.P., Shunkov, M.V., 2004. Formation of the Upper Paleolithic Traditions in the Altai. Archeology, Ethnology and Anthropology of Eurasia, 3, 12-40.

Derevianko A.P., Tsevendorj D., Olsen D., Gladyshev S.A., Rybin E.P., Tserendagva Ya., Chargynov T.T., Bolorbat Ts., 2006. Archaeological research of multilayer site Tolbor-4 in 2006. In: The materials of annual session of Institute of Archeology and Ethnography SB RAS. Novosibirsk: IAET SB RAS, pp. 114.

Derevianko, A.P., Zenin, A.N., Rybin, E.P., Gladyshev, S.A., Tsybankov, A.A., Olsen, J.W., Tseveendorj, D., Gunchinsuren, B., 2007. The technology of early Upper Paleolithic lithic reduction in Northern Mongolia: The Tolbor-4 site. Archaeology, Ethnology and Anthropology of Eurasia 29, 16-38.

Fitzhugh, W.W., 2009. The Mongolian deer stone-khirigsuur complex: dating and organization of a Late Bronze Age menagerie. In: J. Bemmann, H. Parzinger, E. Pohl \& D. Tseveendorzh (Eds.) Current Archaeological Research in Mongolia, (Bonn Contributions to Asian Archaeology 4.) Bonn: vfgarch.press uni-bonn, 183-99.

Germonpré, M., Lbova, L., 1996. Mammalian remains from the Upper Palaeolithic Site of Kamenka, Buryatia (Siberia). Journal of Archaeological Science 23 (1), 35-57.

Gillam, J. C., Gladyshev, S.A., Tabarev, A.V., Olsen, J.,2012. Halfway to Mörön: Shedding new light on Paleolithic landscapes of northern Mongolia. Legacy 16 (2), 14-17. 
Gladyshev, S.A., Olsen, J., Tabarev, A.V., Kuzmin, Y.V., 2010a. Chronology and periodization of Upper Paleolithic sites in Mongolia. Archaeology, Ethnology and Anthropology of Eurasia 38, 33-40.

Gladyshev, S.A., Bolarbat, T., Otsuren, D., Tabarev, A.V., 2010b. Raskopki mnogosloynogo paleoliticheskogo pamyatnika Tolbor-15 v 2010 gody (Excavation at the multilayered Paleolithic site of Tolbor 15, campaign 2010). Problems of Archeology, Ethnography and Anthropology in Siberia and Neighboring Territories 26, 37-40.

Gladyshev, S.A., Olsen, J.W., Tabarev, A.V., Jull, A.J., 2012. The Upper Paleolithic of Mongolia: Recent finds and new perspectives. Quaternary International 281, 36-46.

Gladyshev, Gunchinsuren, Jull A. J. T., Dogandzic, T, , Zwyns, N., Olsen, J. W., Richards, M. P., Tabarev, A. V., Talamo, S., 2013. Radiocarbon dating of Paleolithic sites in the Ikh-Tulberiin-Gol River Valley, Northern Mongolia. Vestnik 12 (5), 44-48.

Goebel, T., Aksenov, M. 1995. Accelerator radiocarbon dating of the initial Upper Paleolithic in southeast Siberia. Antiquity 69, 115-123.

Goebel, T., Derevianko, A.P., Petrin, V.T., 1993. Dating the middle-to-upper-paleolithic transition at Kara-Bom. Current Anthropology 34, 452.

Goebel, T., 2004. The Early Upper Paleolithic of Siberia. In: Brantingham, P.J., Kuhn, S.L., Kerry, K.W. (Eds.), The Early Upper Paleolithic beyond Western Europe. University of California Press, Berkely, pp. 162-195.

Harris, N., Hunt, A. Parkinson, I., Tindle, A., Magisuren, Y., Hammond, S., 2010. Tectonic implications of garnet-bearing mantle xenoliths exhumed by Quaternary magmatism in the Hangay dome, central Mongolia. Contributions to Mineralogy and Petrology 160 (1), 67-81.

Hublin, J.-J., 2012. The earliest modern human colonization of Europe. Proceedings of the National Academy of Sciences of the United States of America 109 (34), 13471-13472. 
Hublin, J.-J., Talamo, S., Julien, M., David, F., Connet, N., Bodu, P., Vandermeersch, B., Richards, M.P., 2012. Radiocarbon dates from the Grotte du Renne and Saint-Césaire support a Neandertal origin for the Châtelperronian. Proceedings of the National Academy of Sciences of the United States of America 109 (46), 18743-18748.

Hunt, A.C., Parkinson, I.J., Harris, N.B.W., Barry, T.L., Yondon, M., 2012. Cenozoic volcanism on the Hangai Dome, Central Mongolia: Geochemical evidence for changing melt sources and implications for mechanisms of melting. Journal of Petrology 53 (9), 1913-1942

Janz, L., Elston, R.G. Burr, G.S., 2009. Dating North Asian surface assemblages with ostrich eggshell: implications for palaeoecology and extirpation. Journal of Archaeological Science 36 (9), 19821989.

Jaubert, J., Bertran, P., Fontugne, M., Jarry, M., Lacombe, S., Leroyer, C., Marmet, E., Taborin, Y., Tsogtbaatar, Brugal, J.P., Desclaux, F., Poplin, F., Rodiere, J., Servelle, C., 2004. Le Paléolithique supérieur ancien de Mongolie: Dörölj-1 (Egiïn Gol). Analogies avec les données de l’Altaï et de Sibérie. In: Le Secrétariat du Congrès (Ed.), The Upper Palaeolithic General Sessions and Posters. Acts of the XIVth UISPP Congress, University of Liège, Belgium, 2-8 September 2001. Archaeopress, Oxford, pp. 245-251.

Kandel, A.W., Conard, N.J., 2005. Production sequence of ostrich eggshell beads and settlement dynamics in the Geelbek Dunes of the Western Cape, South Africa. Journal of Archaeological Science $32,1711-1721$.

Khenzykhenova, F., Sato, T., Lipnina, E., Medvedev, G., Kato, H., Kogai, S., Maximenko, K., Novosel'zeva, V., 2011. Upper Paleolithic mammal fauna of the Baikal region, east Siberia (new data). Quaternary International 231 (1-2), 50-54.

Klinken, G.J.V., 1999. Bone collagen quality indicators for palaeodietary and radiocarbon measurements. Journal of Archaeological Science 26, 687-695. 
Kromer, B., Lindauer, S., Synal, H.-A., Wacker, L., 2013. MAMS - A new AMS facility at the CurtEngelhorn-Centre for Achaeometry, Mannheim, Germany. Nuclear Instruments and Methods in Physics Research Section B: Beam Interactions with Materials and Atoms 294, 11-13.

Kuhn, S. L., Zwyns, N., 2014. Rethinking the Initial Upper Paleolithic. In this volume.

Kuhn, S., Stiner, M., Güleç, E., 1999. Initial Upper Paleolithic in south-central Turkey and its regional context: a preliminary report. Antiquity 73, 505-517.

Kuzmin, Y., 2004. Origin of the Upper Paleolithic in Siberia. In: Brantingham, P.J., Kuhn, S.L. Kerry, K.W. (Eds.), The Early Upper Paleolithic beyond Western Europe. University of California Press, Berkeley, pp. 196-206.

Kuzmin, Y., 2007. Geoarchaeological aspects of the origin and spread of microblade technology in northern and central Asia. In: Kuzmin, Y.V., Keates, S.G., Shen, C. (Eds.), Origin and Spread of Microblade Technology in Northern Asia and North America. Archaeology Press, Simon Fraser University, Burnaby, British Columbia, pp. 115-124.

Lbova, L., 2008. Chronology and paleoecology of the Early Upper Paleolithic in the Transbaikal region (Siberia). Eurasian Prehistory 5, 109-114.

Lenoble, A., Bertran, P., 2004. Fabric of Palaeolithic levels: methods and implications for site formation processes. Journal of Archaeological Science 31, 457-469.

Longin, R., 1971. New method of collagen extraction for radiocarbon dating. Nature 230, 241-242.

McPherron, S. P., 2005. Artifact orientations and site formation processes from total station proveniences. Journal of Archaeological Science 32 (7), 1003-1014.

McPherron, S., Dibble, H., 2002. Using Computers in Archaeology: A Practical Guide. McGraw Hill, New York. 
Nigst, P.R., Viola, T.B., Haesaerts, P., Blockley S., Damblon, F., Frank, C., Fuchs, M., Götzinger, M., Hambach, U., Mallol, C., Moreau, L., Niven L., Richards, M., Richter, D., Zöller, L., Trnka, G., Hublin, JJ., 2008. New research on the Aurignacian of Central Europe: A first note on the 2006 fieldwork at Willendorf II. Quartär 55, 9-15.

Orlova, L., Kuzmin, Y., Lbova, L., 2005. Radiouglerodnye daty pamyatnikov paleolita i mezolita Zabaikalya i Mongolii (Radiocarbon dates of the Paleolithic and Mesolithic of the Transbaikal and Mongolia). In: Paleoliticheskie Kultury Zabaikalya I Mongolii (Novye Fakty, Metody I Gipotezy). Novosibirsk, pp. 88-92.

Orton, J., 2008. Later Stone Age ostrich eggshell bead manufacture in the Northern Cape, South Africa. Journal of Archaeological Science 35, 1765-1775.

Otte, M., Derevianko, A.P. 2001. The Aurignacian in Altai. Antiquity, 75, 44-49.

Otte, M., Kozlowski, J. K. 2005. The transition from the Middle to Upper Paleolithic in north Eurasia. In: Derevianko, A.P. (Ed.) The Middle to Upper Paleolithic transition in Eurasia: hypotheses and facts, Novosibirsk: Institute of Archaeology and Ethnography Press, pp. 20-31.

Pelegrin, J., 1995. Technologie lithique: le Châtelperronien de Roc-de-Combe (Lot) et de La Cote (Dordogne). CNRS edition, Paris.

Pelegrin, J., Inizan, M.-L., 2013. Soft hammerstone percussion use in bidirectional blade-tool production at Acila 36 and in bifacial knapping at Shagra (Qatar). Arabian Archaeology and Epigraphy 24, 79-86.

Rybin, E., 2004. Middle Paleolithic "Blade" Industries and the Middle-to-Upper-Paleolithic Transition in South Siberia: Migration or Regional Continuity? BAR International Series 1239, pp. 81-90.

Rybin, E.P., 2014. Tools, beads, and migrations: Specific cultural traits in the Initial Upper Paleolithic of Southern Siberia and Central Asia. In this volume. 
Rybin, E.P., Gladyshev, S.A., Tsybankov, A.A., 2007. Vozniknovenje i razvitie "otshepovikh" industry ranney pory verkhnego paleolita Severnoy Mongolii (Emergence and development of another Early Upper Paleolithic industry in Northern Mongolia). In: Severnaya Evrasia V Anthropologenie. Chelovek Paleolitechnologii, Geoecologia, Ethnografii I Anthropologii, pp. 137-152.

Schick, K.D., 1986. Stone Age Sites in the Making. BAR International Series 139.

Simonet, A., Tseveendorj, D., Goutas, N., Magail, J. Moulle, P-E., Arrellano, A., 2012. Tsatsyn Ereg 2: campagne 2012 de la mission archeologique Monaco-Mongolie. Bulletin de la Musée d'Anthropologie et Préhistoire, Monaco 52, 114-124.

Tabarev, A.V., B. Gunchinsuren, Gillam, J. Ch., Gladyshev, S. A., Dogandzic, T., Zwyns, N. Bolorbat, Ts., Odsuren, D., 2012. Kompleks Pamiatnikov Kamennogo Veka v Doline r.Ikh Tulberiin-Gol, Severnaya Mongolia (razvedochnye raboty s ispolzovaniem GIS-Technnologii v 2011 g.)1. Studia Archaeologica Insituti Archaeologici Academiae Scientiarum Mongolicae 32 (2), 26-43.

Talamo, S., Richards, M., 2011. A comparison of bone pretreatment methods for AMS dating of samples >30, 000 BP. Radiocarbon 53, 443-449.

Tashak, V., 2002. Podzvonkaya: Paleoliticheskie Materialy Nizhnego Kompleksa (Buryatia) - (The Podzvonkaya Site: Paleolithic Materials from the Lower Complex (Buryatia). In: Kradin, N.N. (Ed.), Arkheologiya I Kulturnaya Antropologiya Dalnego Vostoka I Tsentralnoi Azii. Vladivostok, pp. 2533.

Weber, A.W., McKenzie H.G., Beukens R., Goriumova, O.I., 2005. Evaluation of radiocarbon dates from the Middle-Holocene hunter-gatherer cemetery Khuzhir-Nuge XIV, Lake Baikal, Siberia. Journal of Archaeological Science 32, 1481-1500.

Zwyns, N., 2012. Laminar Technology and the Onset of the Upper Paleolithic in the Altai, Siberia. Studies in Human Evolution, Leiden University Press, Leiden. 
Zwyns, N., Rybin, E.P., Hublin, J.J., Derevianko, A.P., 2012. Burin-Core Technology \& Laminar Reduction sequence in the Initial Upper Paleolithic from Kara-Bom (Gorny-Altai, Siberia). Quaternary International 259 (9), 33-47. 


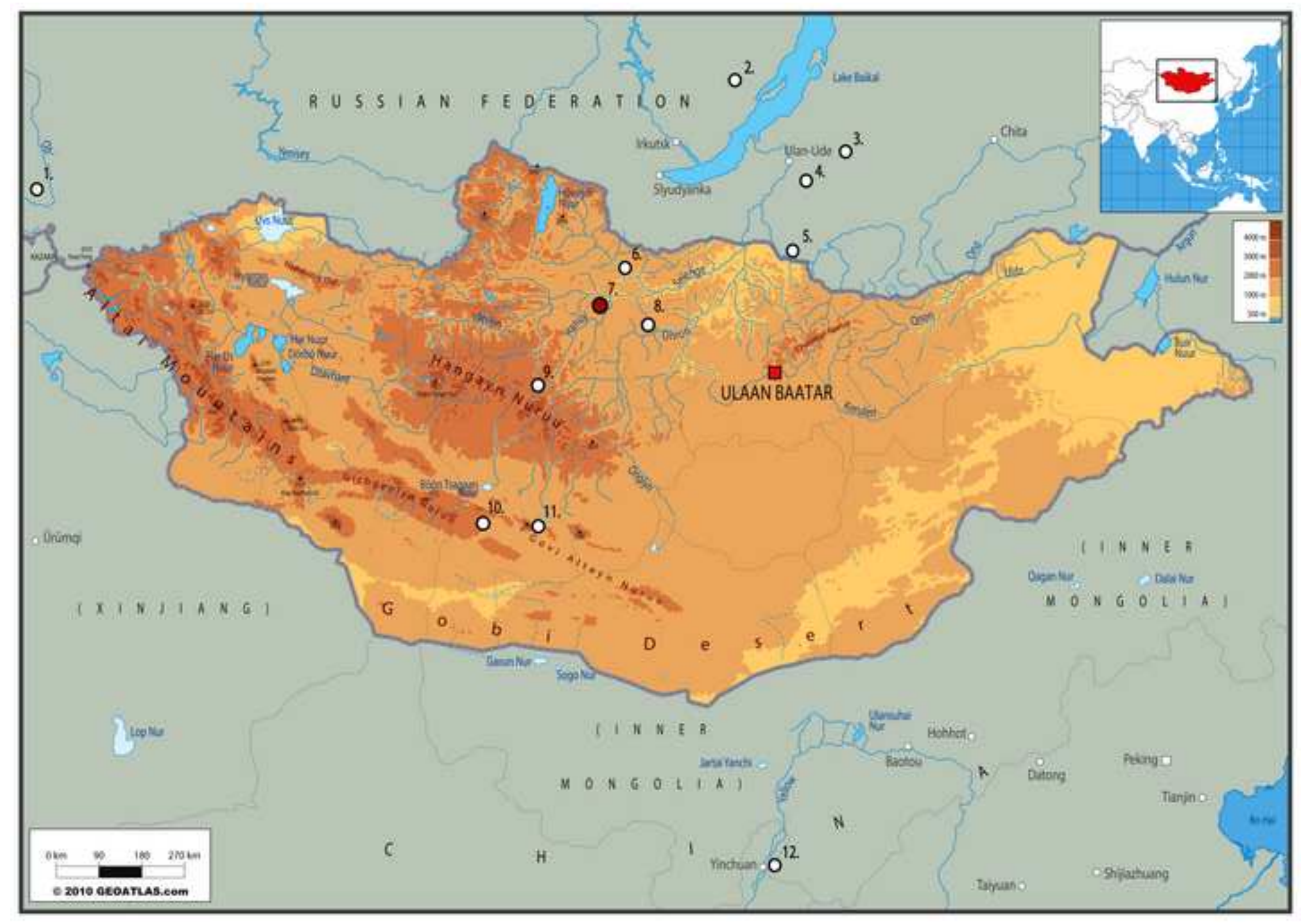




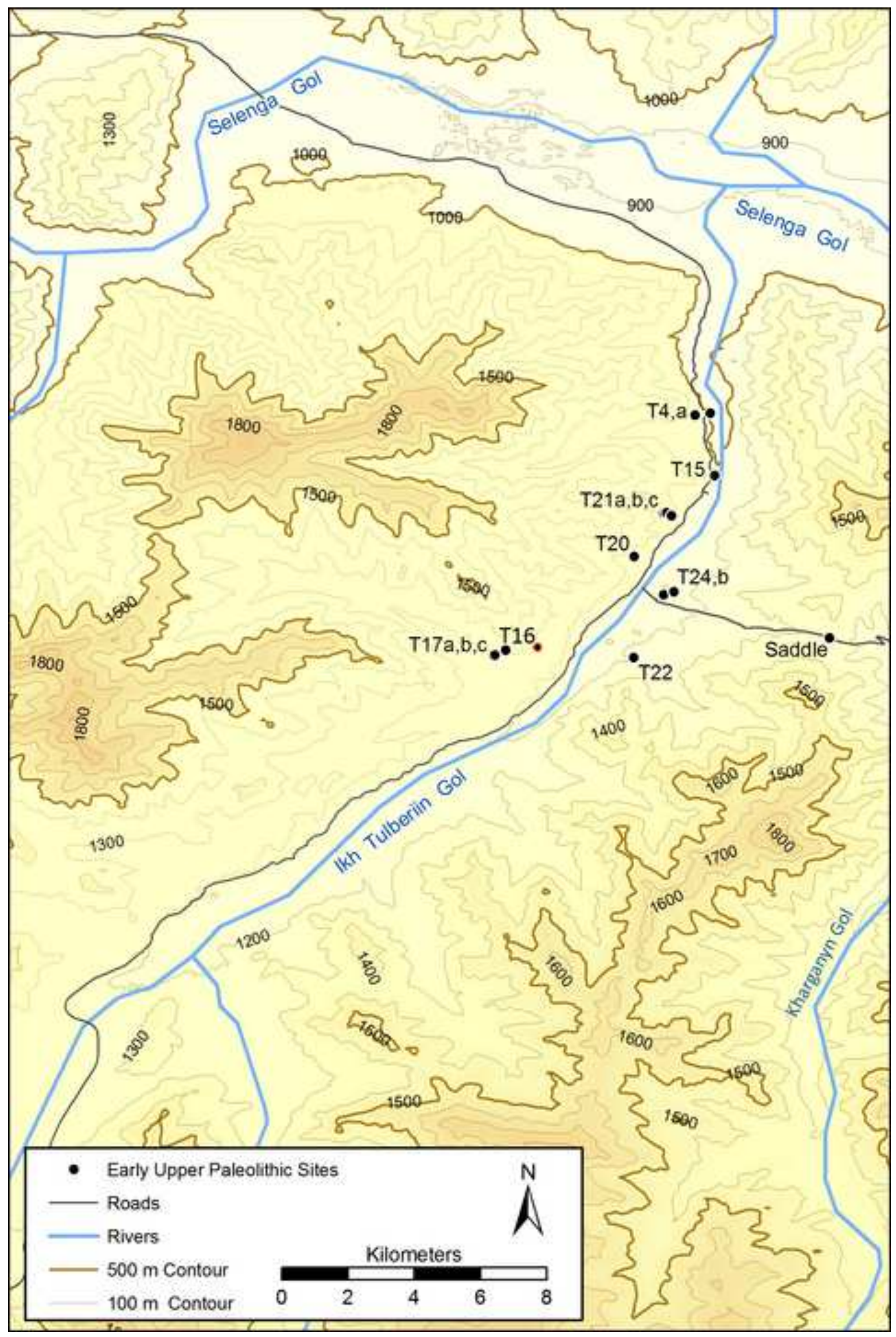


Figure
Click here to download high resolution image

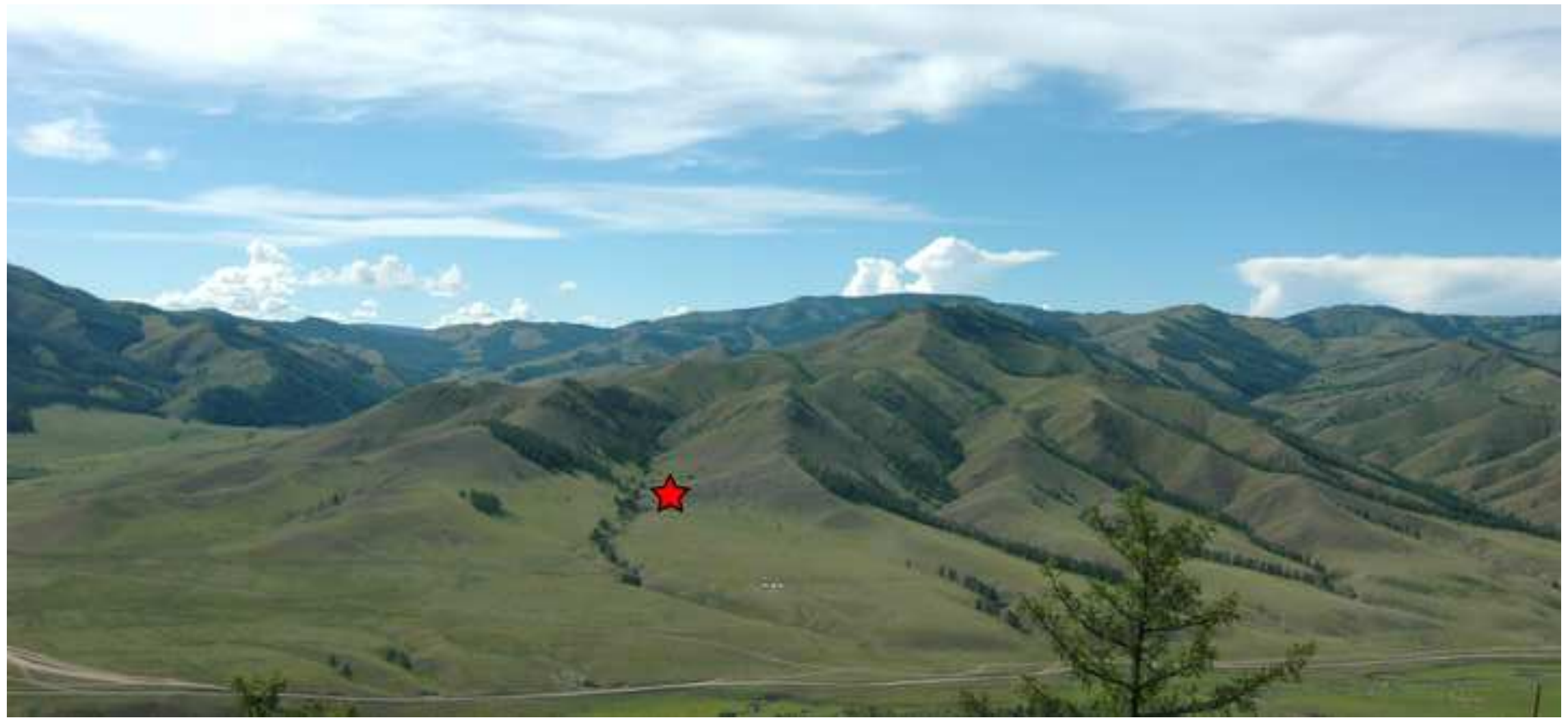


Figure

Click here to download high resolution image

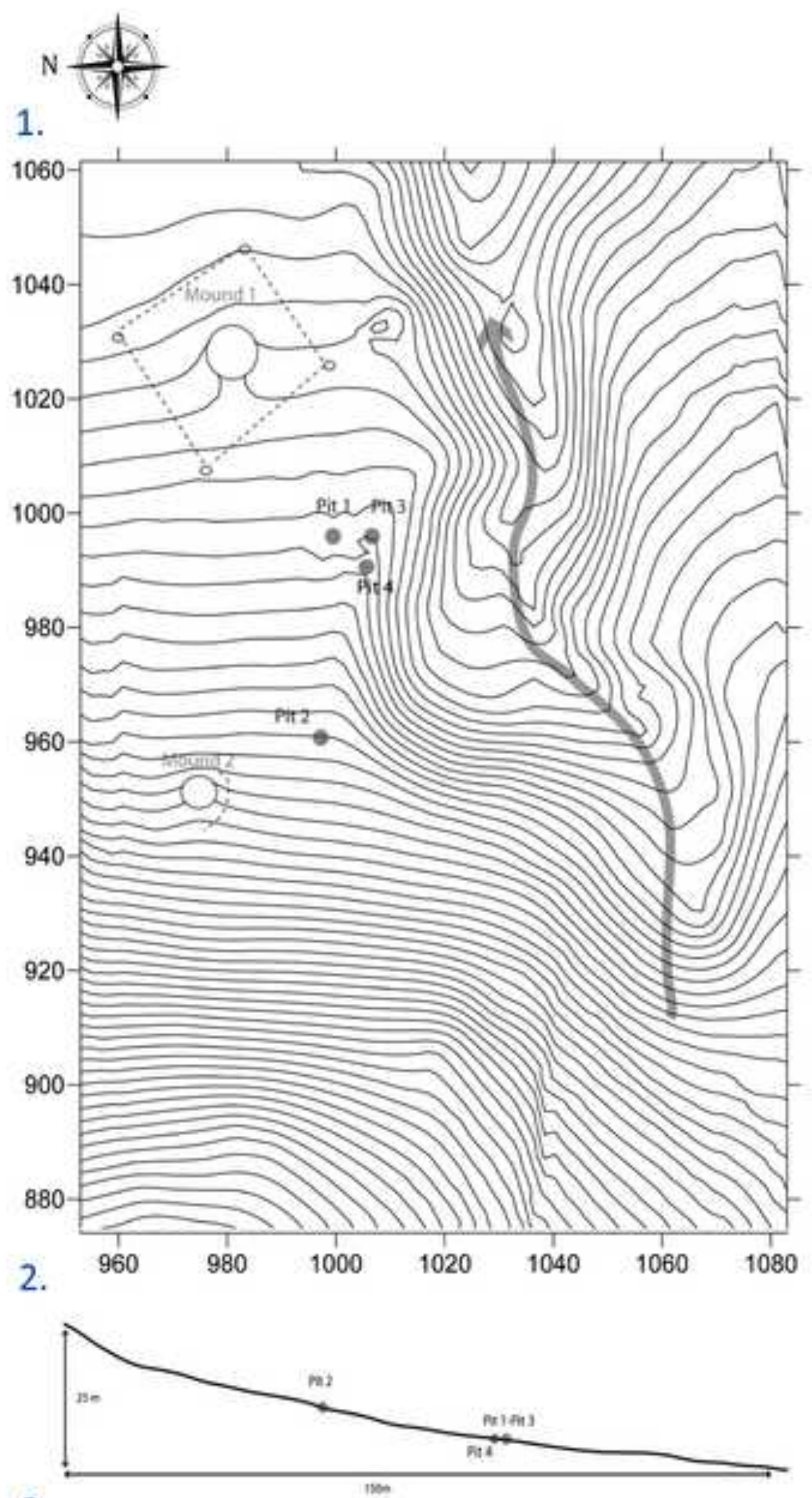

3.

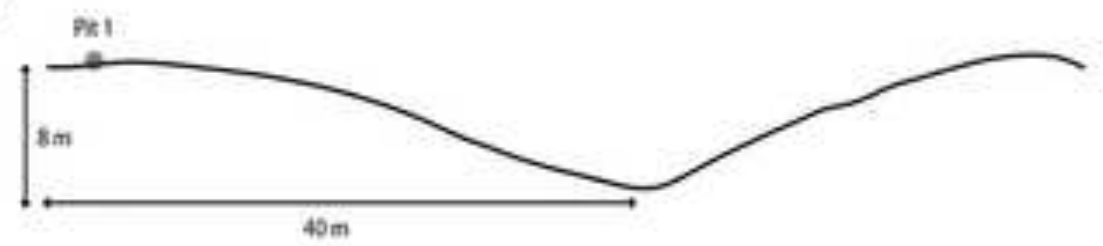


Click here to download high resolution image

993

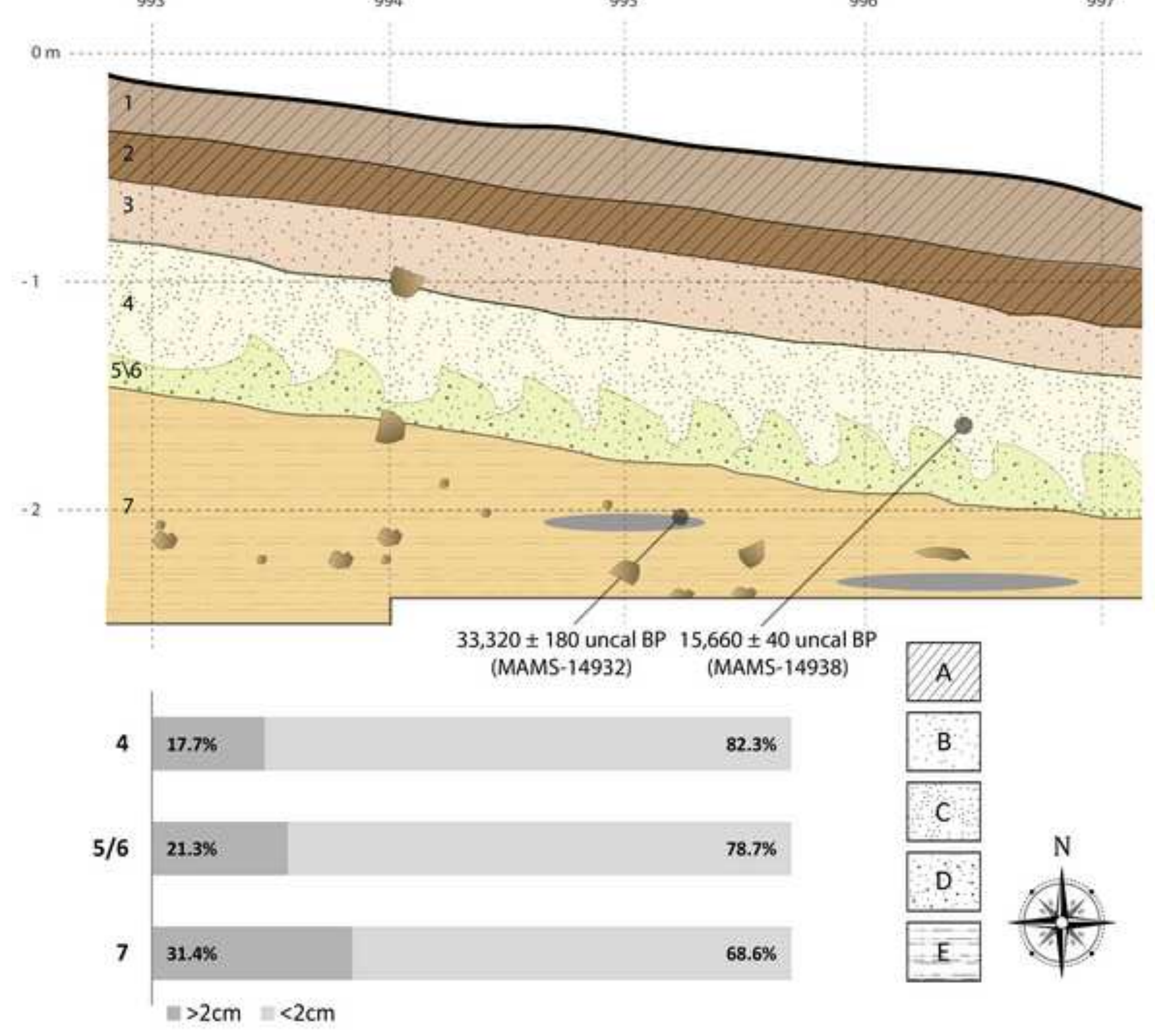


Figure

Click here to download high resolution image
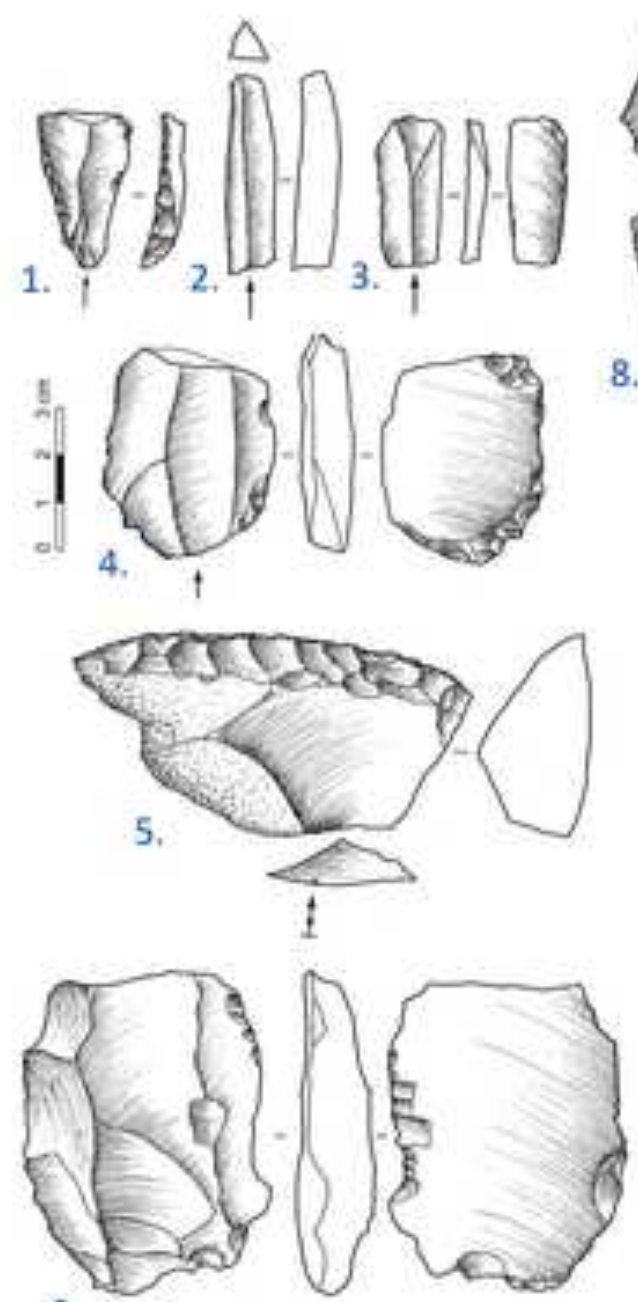

6. $\frac{1}{1}$
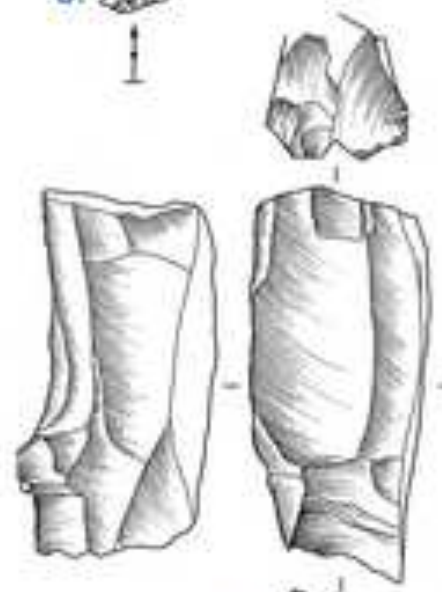

7.

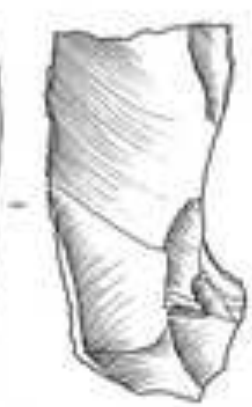

11.
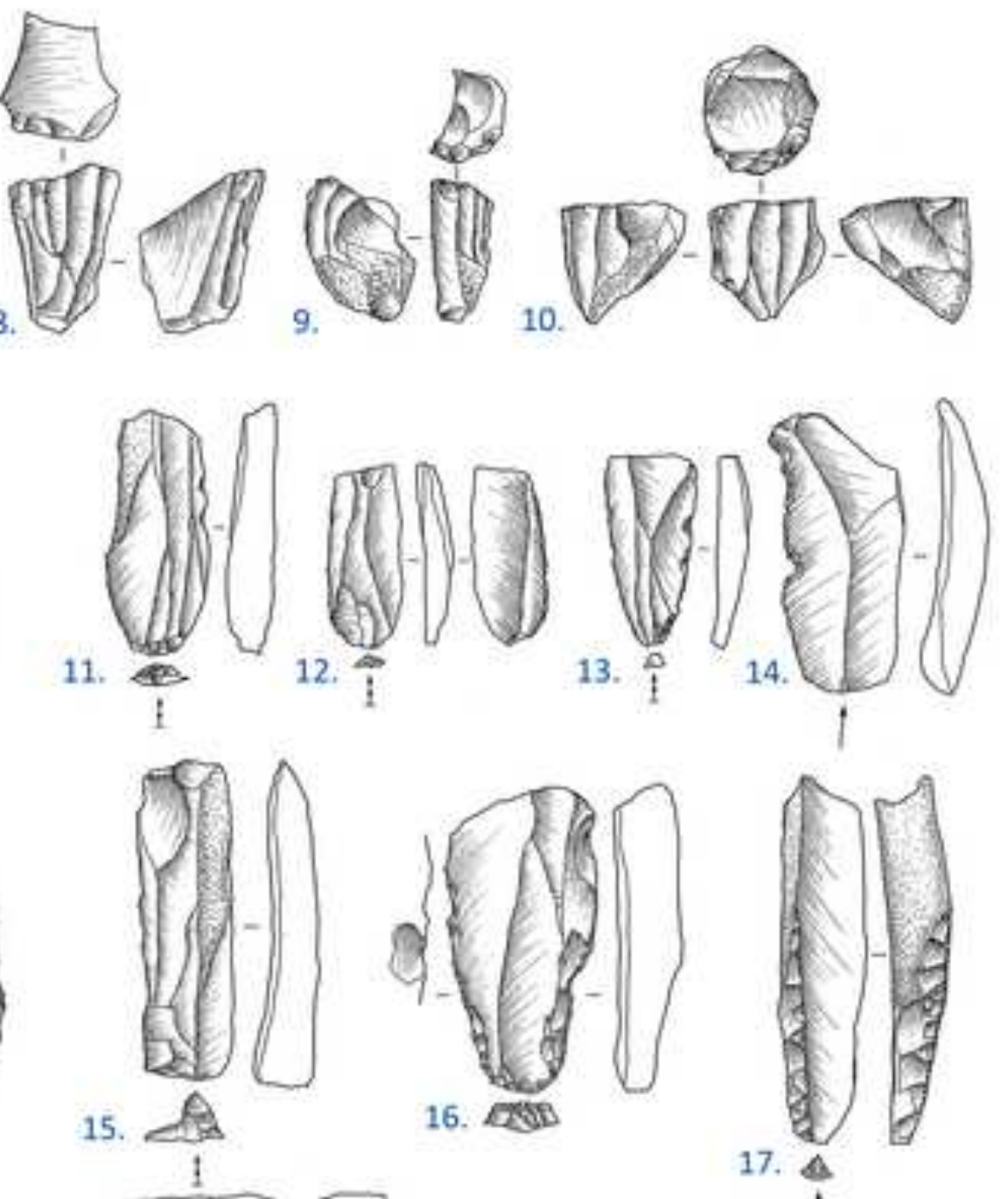

16. 025
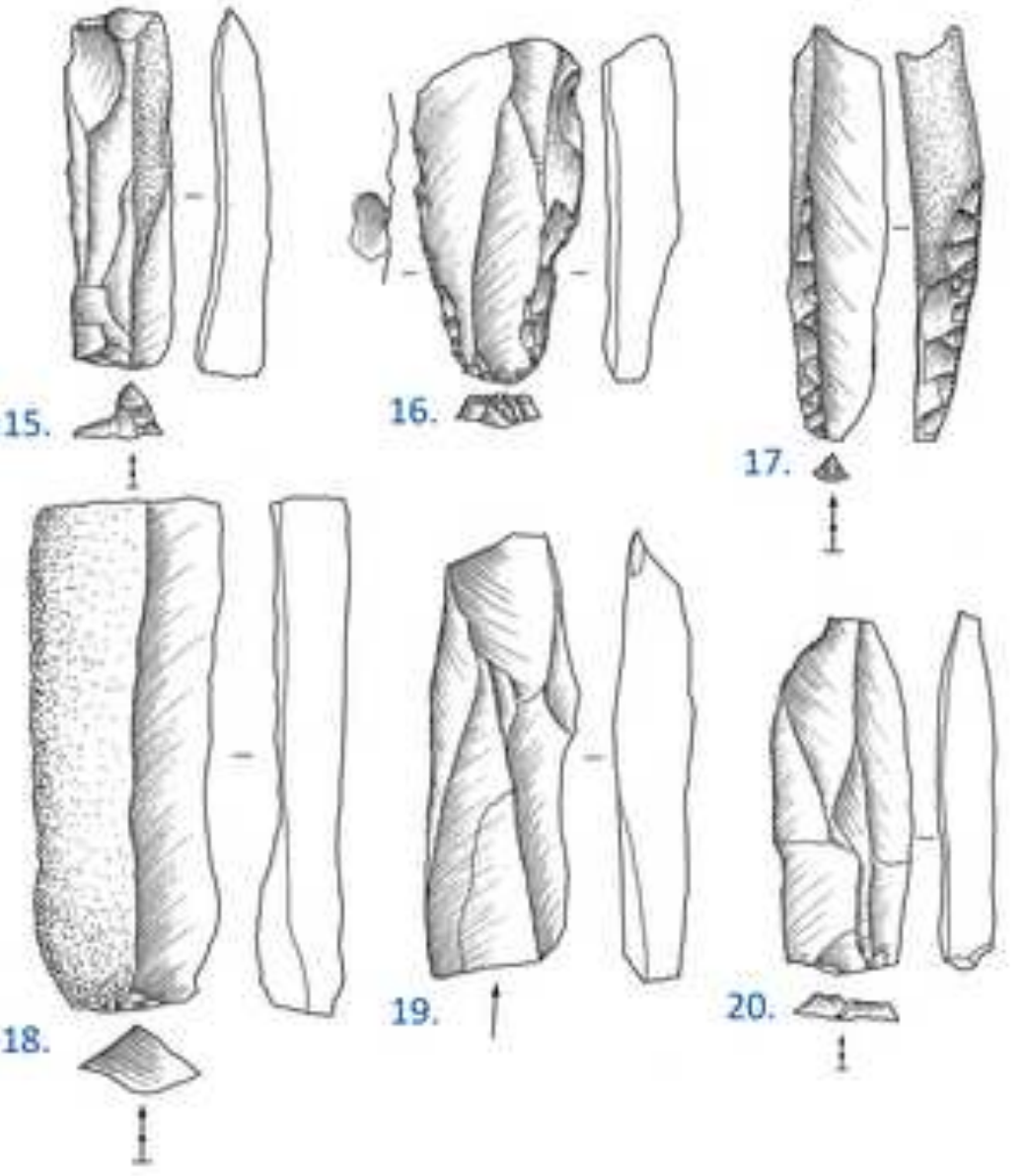

17 


\section{Figure}

Click here to download high resolution image
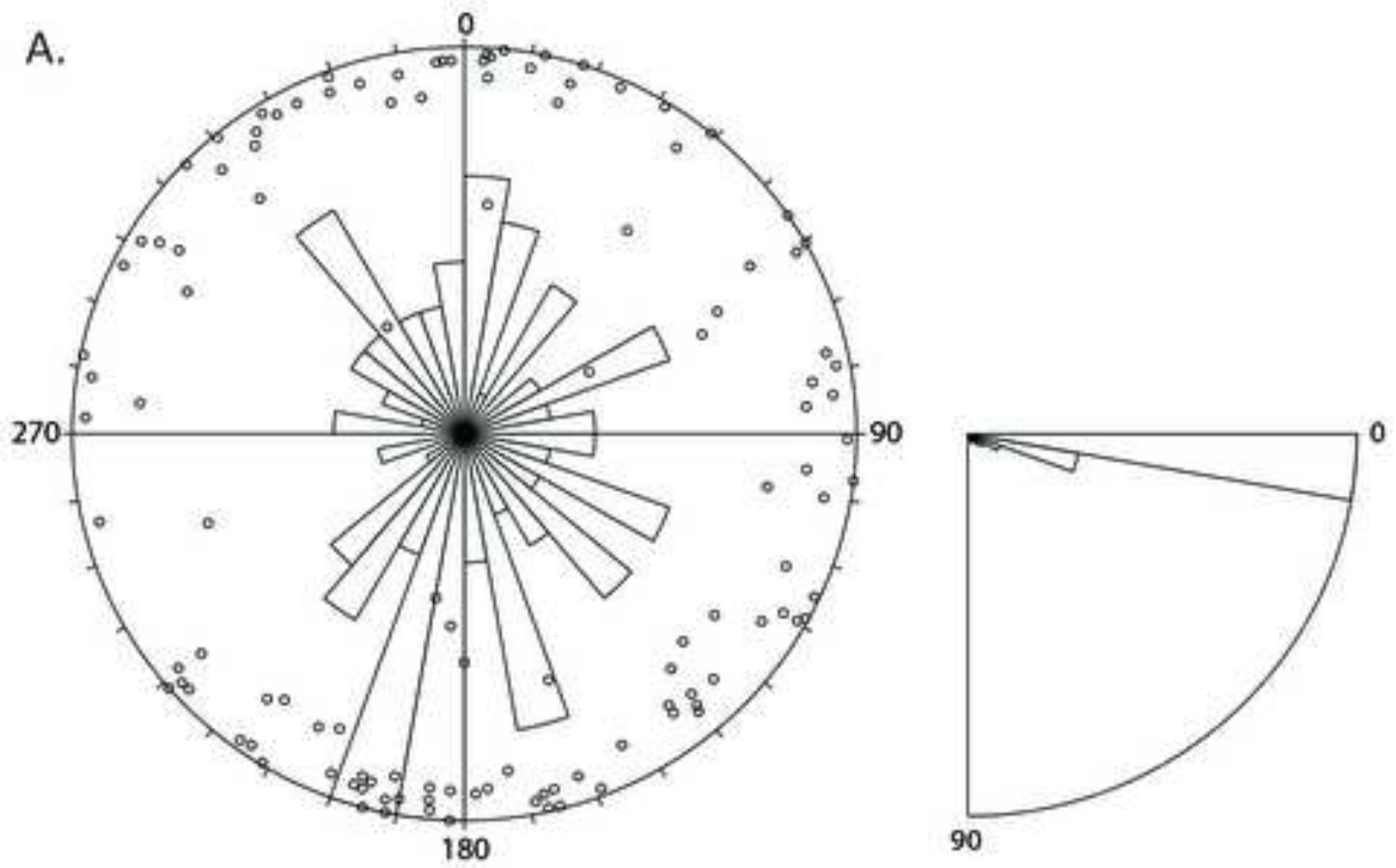

B.

Isotropic

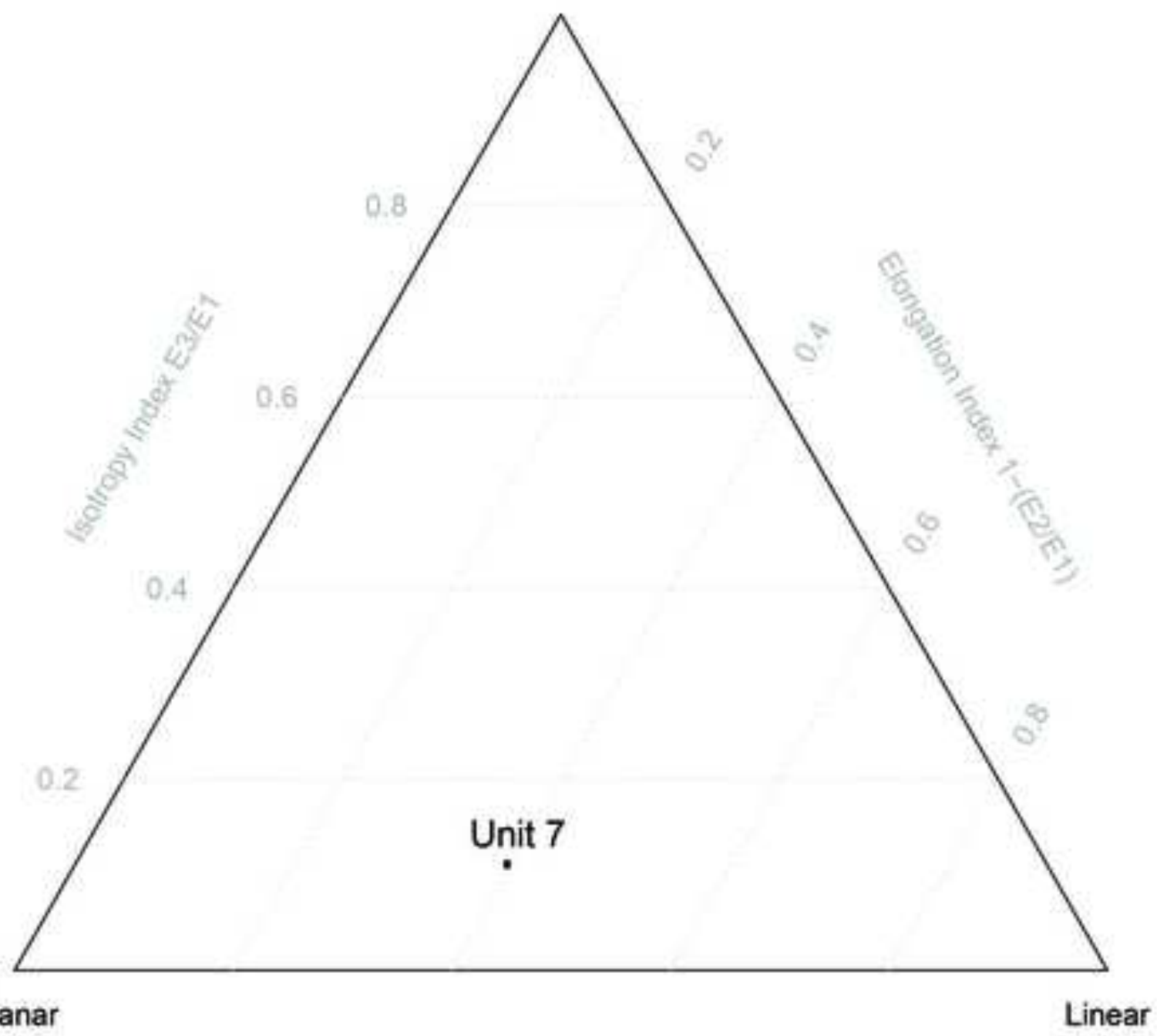




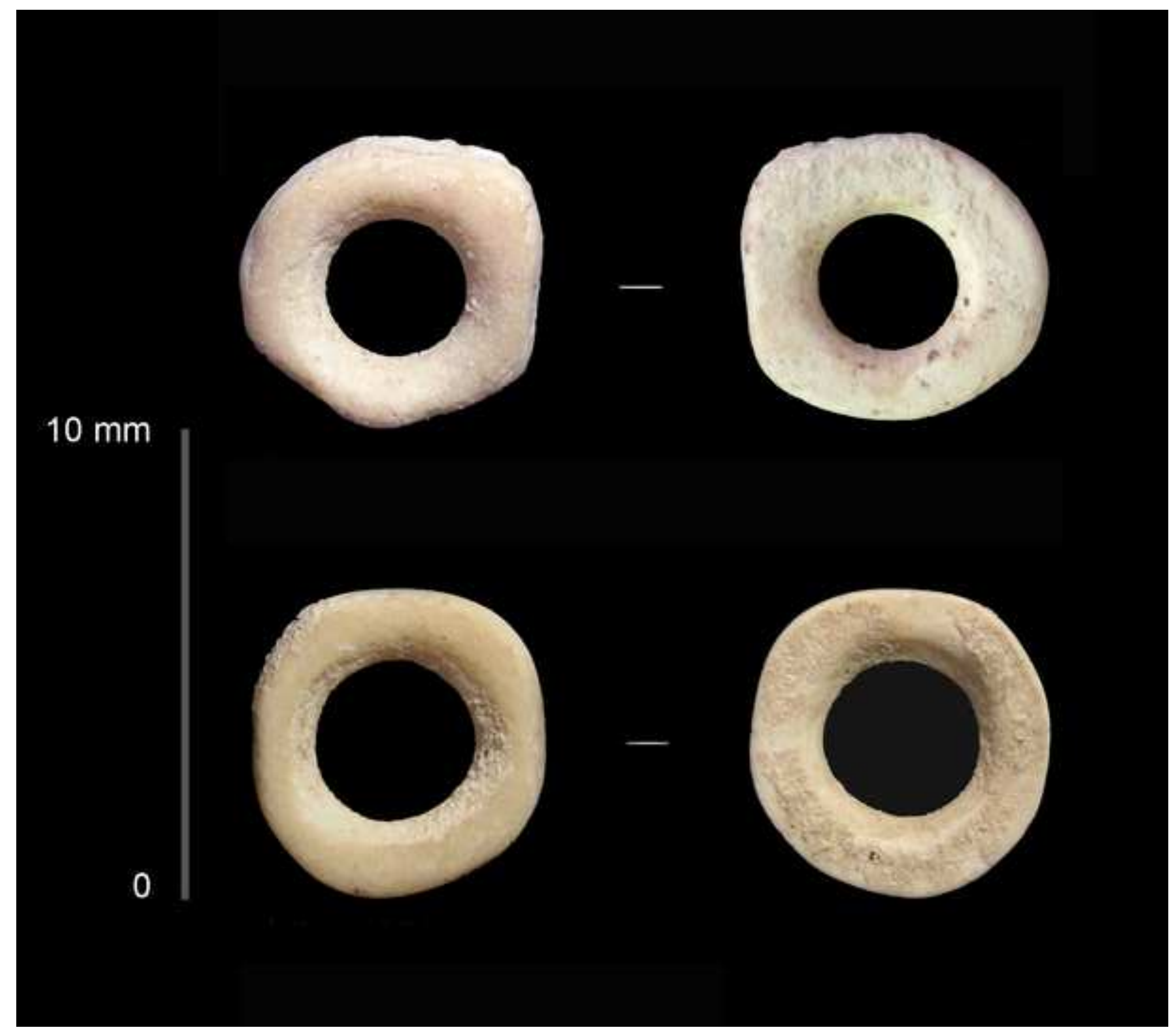

$10 \mathrm{~mm}$ 
Table

Table1

\begin{tabular}{cccccc}
\hline $\mathbf{N}$ & E1 & E2 & E3 & IS & EL \\
\hline 121 & 0.579 & 0.35 & 0.063 & 0.11 & 0.396 \\
\hline
\end{tabular}


Table2

\begin{tabular}{ccccccccccccccc}
\hline & \multicolumn{2}{c}{$\begin{array}{c}\text { Core/ } \\
\text { preform }\end{array}$} & \multicolumn{2}{c}{ Flake } & \multicolumn{2}{c}{ Blade } & \multicolumn{2}{c}{ Bladelet } & Undetermined & Shatter & Total \\
& $\mathrm{N}$ & $f$ & $\mathrm{~N}$ & $F$ & $\mathrm{~N}$ & $f$ & $\mathrm{~N}$ & $F$ & $\mathrm{~N}$ & $f$ & $\mathrm{~N}$ & $F$ & $\mathrm{~N}$ & $f$ \\
\hline Unretouched & 53 & 0.05 & 199 & 0.18 & 197 & 0.18 & 10 & 0.01 & 37 & 0.03 & 420 & 0.39 & 914 & 0.85 \\
\hline Retouched & $/$ & 0.00 & 57 & 0.05 & 94 & 0.09 & 2 & 0.00 & 9 & 0.01 & $/$ & 0.00 & 160 & 0.15 \\
\hline Total & 53 & 0.05 & 256 & 0.24 & 291 & 0.27 & 12 & 0.01 & 46 & 0.04 & 428 & 0.39 & 1076 & 1.00 \\
\hline
\end{tabular}


Table3

\begin{tabular}{|c|c|c|c|c|c|c|c|c|}
\hline Lab number & ${ }^{14} \mathrm{C}$ BP & Site & Sample location & Sampled material & Collagen $\%$ & $\mathrm{C}: \mathrm{N}$ & $\begin{array}{c}\text { Cal BP } \\
\text { (68\% range } \\
\text { calBP) }\end{array}$ & Attribution \\
\hline AA-93139 & $14547 \pm 73$ & T4 & level 3 & Struthio eggshell & & & $17464-17947$ & UP \\
\hline AA-84135 & $26700 \pm 300$ & T4 & level 4 & Struthio eggshell & & & $30984-31764$ & EUP \\
\hline AA-93140 & $31210 \pm 410$ & T4 & level 5 & Struthio eggshell & & & $34777-35712$ & IUP \\
\hline AA-79326 & $>41050$ & T4 & level 5 & bone & & & $>44608$ & IUP \\
\hline AA-93141 & $35230 \pm 680$ & T4 & level 6 & Struthio eggshell & & & $39137-41120$ & IUP \\
\hline AA-79314 & $37400 \pm 2600$ & $\mathrm{~T} 4$ & level 6 & bone & & & $38878-43829$ & IUP \\
\hline AA-84136 & $14056 \pm 81$ & T15 & level 3 & Struthio eggshell & & & $17076-17521$ & UP \\
\hline Beta-263742 & $14930 \pm 70$ & $\mathrm{~T} 15$ & level 3 & Struthio eggshell & & & $17977-18463$ & UP \\
\hline Beta-263744 & $14680 \pm 70$ & $\mathrm{~T} 15$ & level 4 & Struthio eggshell & & & $17632-18377$ & UP \\
\hline Beta-263745 & $14820 \pm 70$ & $\mathrm{~T} 15$ & level 4 & Struthio eggshell & & & $17889-18432$ & UP \\
\hline AA-84137 & $28460 \pm 310$ & $\mathrm{~T} 15$ & level 5 & Struthio eggshell & & & $32448-33345$ & EUP \\
\hline AA-93136 & $32200 \pm 1400$ & T15 & level 5 & bone & & & $35182-38664$ & EUP \\
\hline AA- 84138 & $29150 \pm 320$ & $\mathrm{~T} 15$ & level 7 & Struthio eggshell & & & $33194-33972$ & EUP \\
\hline AA-93137 & $33200 \pm 1500$ & $\mathrm{~T} 15$ & level 7 & bone & & & $36047-40129$ & EUP \\
\hline MAMS-14934 & $34010 \pm 200$ & $\mathrm{~T} 15$ & level 7 & bone & 5.8 & 3.3 & $38656-40537$ & EUP \\
\hline MAMS-14935 & $33470 \pm 190$ & $\mathrm{~T} 15$ & level 7 & bone & 5.4 & 3.2 & $37426-40318$ & EUP \\
\hline MAMS-14937 & $34340 \pm 210$ & $\mathrm{~T} 15$ & level 7 & bone & 5.3 & 3.2 & $38903-40532$ & EUP \\
\hline MAMS-14938 & $15660 \pm 40$ & $\mathrm{~T} 16$ & Pit 1 unit 4 & bone & 2.0 & 3.3 & $18702-19153$ & UP \\
\hline MAMS-14932 & $33320 \pm 180$ & $\mathrm{~T} 16$ & Pit 1 unit 7 & bone & 2.8 & 3.2 & $37205-38500$ & EUP? \\
\hline AA-93134 & $>45400$ & T16 & test pit (Pit 1) unit 7 & bone & & & $>48612$ & IUP? \\
\hline AA-93135 & $29230 \pm 930$ & $\mathrm{~T} 17$ & test pit 2, level 3 & bone & & & $32742-34351$ & $?$ \\
\hline MAMS-14933 & $44640 \pm 690$ & T21 & test pit 1 , level 4 & bone & 2.3 & 3.2 & $46196-49457$ & IUP? \\
\hline MAMS-14936 & $39240 \pm 360$ & $\mathrm{~T} 21$ & test pit 2, level 3 & bone & 4.4 & 3.2 & $42878-44033$ & IUP? \\
\hline
\end{tabular}


Detailed reply to reviewer

The invitation was originally for a short contribution to place on the map a newly discovered site, with an excavation in progress (quantitative data subject to change). We tried to address most of the comments. Doing so required a re-organization of the paper (that now looks more like a long contribution).

Reviewers' comments:

Reviewer 1: the topic is not one that I know much about, but I thought it was coherent and read well. There are a few minor changes indicated below:

p.4: "The latter is mostly characterized by the presence of a small laminar blanks (Kuzmin, 2004, 2007)" - delete the "a"

p.6, top: "Active Volcanism is well documented in Central and Northern" small "v"

p. 11: Fragments of Ostrich eggshells have been uncovered in Unit 4 and Unit 7. These taxa are not unexpected for deposits of this age Northward from the Hangai (Simonet et al., 2012); small "o" for ostrich; small "n" for northward

p.13: "for the layer 7 at T15. . The single" - delete the extra full stop

References: please check that titles of articles in journals are given in sentence case, i.e. Capital letter only for the beginning of the first word and for proper nouns. (Some are ok, others are not).

All comments have been addressed and corrections made.

(From the editor): I have appended a review by a reviewer who wished to remain anonymous and for various reasons was able to submit the review through the QI on-line system. As you can see, its main criticisms are that more details could be provided, and various aspects of the presentation could be improved. I would be helpful if you could deal with these points; or, if you cannot or do not think it appropriate, please indicate why in your resubmission. My impression from reading these comments and checking your submission is that most are straightforward.

With the figures: 4b (plan of the excavation) - this does not seem very helpful - maybe delete this and add a sentence of two in the text.

This has been removed, details are in the text.

Figure 5a - the photo of the section: check how this looks in B/W; if the details don't show, a drawn section might be clearer, with appropriate text.

This has been addressed. There is now a section schema instead of the picture, with call for fig. in the text.

reviewer 2 (anonymous)

This is a very preliminary site report. Even if a site report is what is required for this special issue, there is very little information provided, and, as such, it is very difficult for the authors to justify their claims of connection with other sites in the region or larger issues in human 
evolution. I recommend the authors resubmit the paper, inserting more information, supporting their claims with some basic, simple statistics, and presenting the data in a better graphical way, as I outline below.

The treatment of the lithics (and fauna) is so general (in contrast to the stratigraphy, where subsoil content is described), and most statements are so vague that it is impossible to extract any meaning from them. For example:

"A production of convergent flakes with hard-hammer percussion is found associated with evidence for the production of microblades by pressure flaking. Highly fragmented blades of small and medium size are identified." What's the proportion of hard-hammer to soft-hammer and pressure flakes? What method was used to identify these? (hard vs. soft-hammer is an interpretation, not a direct observation). And what is "small and medium size"??? (on the same page, Unit 7 seems to also have "large-size sidescrapers"). At least some sample of these should have been measured, and these measurements reported.

Description of unit 7 lithic assemblage now includes quantitative data and basic descriptive statistics. Details on unit 4 have been removed.

Again, from the lithics section:

"Among the blade blanks, some show specific platform preparations with an intensively abraded or bludgeoned external platform edge. A few bladelet cores have been uncovered in the upper part of Unit 7 a and at the interface (Unit 5/6)."

"some" and "a few" is just not good enough for print. Please provide some kind of basic quantification.

\section{Addressed}

Regarding the fauna, some kind of basic pie or bar chart showing proportions of identified bones and teeth by taxon and unidentifiable fragments would be appreciated.

Study in progress, no additional data available

Likewise, a photograph of the combustion features and the beads would strengthen the article. It is not very useful to mention these without some graphical evidence.

Study in progress, no additional data available for the combustion features.

Picture of the beads and brief descriptions have been added.

Figures:

Despite the detailed description of the stratigraphy and the accompanying profile photograph in Figure 5, the article would be greatly improved by an associated section drawing, as the details are hard to see on the photo. Moreover, there is a lot of talk of layers truncating each other downslope, but this is difficult to imagine given the current graphical presentation 
(without the slope). Likewise, the artifact frequencies and radiocarbon dates should also appear on this figure, helping the reader get a full picture with one look. Furthermore, I am not entirely convinced that there is no alignment in the Schmidt diagram in Figure 5. Can the authors please provide a statistical assessment of this (e.g., from the article cited by themselves, McPherron 2005)?

Stratigraphy + dates +artifact frequency: addressed

Artifact orientation: addressed (see in the text + figure 6 \& table 1)

Finally, I think the paper would benefit from taking the radiocarbon dates from the table and putting them on the map in Figure 2. It is only a suggestion, but long tables with dates that are in an arbitrary sequence (alphanumeric) are hard to read. Putting them in a geographic context would be much better.

Dates: too many dates/multilayered sites to place on a map. It is here the first published summary of these chronological data for this region, so we think that it is important to display the raw data. The table is not completely arbitrary; it is organized by sites/layers/labs. We added cultural attribution (when possible) and calibrated results at 1 sigma. 